\title{
A High-Latitude Convective Cloud Feedback and Equable Climates
}

\section{Citation}

Abbot, Dorian S., and Eli Tziperman. 2008. A high latitude convective cloud feedback and equable climates. Quarterly Journal of the Royal Meteorological Society 134(630): 165-185.

\section{Published Version}

http://dx.doi.org/10.1002/qj.211

\section{Permanent link}

http://nrs.harvard.edu/urn-3:HUL.InstRepos:3444550

\section{Terms of Use}

This article was downloaded from Harvard University's DASH repository, and is made available under the terms and conditions applicable to Other Posted Material, as set forth at http:// nrs.harvard.edu/urn-3:HUL.InstRepos:dash.current.terms-of-use\#LAA

\section{Share Your Story}

The Harvard community has made this article openly available.

Please share how this access benefits you. Submit a story.

Accessibility 


\title{
A high-latitude convective cloud feedback and equable climates
}

\author{
Dorian S. Abbot ${ }^{\mathrm{a} *}$ and Eli Tziperman ${ }^{\mathrm{a}, \mathrm{b}}$ \\ a School of Engineering and Applied Sciences, Harvard University, Cambridge, MA, USA \\ ${ }^{\mathrm{b}}$ Department of Earth and Planetary Sciences, Harvard University, Cambridge, MA, USA
}

\begin{abstract}
A convective cloud feedback on extratropical surface temperatures is identified in a zonally averaged twolevel atmospheric model. The model contains simplified parametrizations for convection, precipitation, and clouds, and a long-wave radiation scheme that explicitly depends on carbon dioxide, water vapour, and cloud fraction. The convective cloud feedback occurs if the extratropical surface temperature is increased enough to initiate strong atmospheric convection. This results in a change from low to high clouds and from negative to neutral or positive cloud radiative forcing, which further warms the surface and leads to more convection. This positive feedback activates as the $\mathrm{CO}_{2}$ concentration is increased and leads to a climate solution with high boundary-layer temperatures, convection at mid and high latitudes, and an Equator to Pole temperature difference that is reduced by $8-10^{\circ} \mathrm{C}$. The reduction in Equator to Pole temperature difference is due to changes in high-latitude local heat balance and occurs despite decreased meridional heat transport. The convective cloud feedback also leads to multiple equilibria and hysteresis with respect to $\mathrm{CO}_{2}$ and other model variables, although these results may be due to the simplicity of the model. The possible connection of the behaviour of the model at high $\mathrm{CO}_{2}$ with equable climates is considered. Copyright (C) 2008 Royal Meteorological Society
\end{abstract}

KEY WORDS cloud radiative forcing; Cretaceous; Eocene; Paleogene

Received 10 October 2007; Revised 19 December 2007; Accepted 19 December 2007

\section{Introduction}

A plethora of paleoclimatic data exists suggesting that Earth's climate during the late Cretaceous period $(\sim 100$ to $\sim 65.5$ million years ago, Ma) and the early Paleogene period ( $\sim 65.5$ to $\sim 34 \mathrm{Ma})$ was vastly different from Earth's modern climate. Oxygen isotopic ratios in the shells of Foraminifera indicate that during these periods the tropical sea surface temperatures (SSTs) were a few degrees Celsius higher than they are at present (Pearson et al., 2001; Norris et al., 2002; Tripati et al., 2003; Roche et al., 2006), whereas deep ocean temperatures were $8-12^{\circ} \mathrm{C}$ (Zachos et al., 2001), much higher than their modern value of $0-3^{\circ} \mathrm{C}$. Provided deep ocean water was formed at high latitudes during the late Cretaceous and early Paleogene, as it is currently, high deep-water temperatures can be interpreted as indicating high highlatitude SSTs. Direct proxy data of high-latitude SSTs supports this supposition. Foraminiferal oxygen isotopic ratios suggest SSTs were $10-15^{\circ} \mathrm{C}$ at about $75^{\circ}$ paleolatitude (Zachos et al., 1994), oxygen isotopic ratios in the shells of molluscs suggest that SSTs in coastal regions of the Arctic Ocean were about $10-15^{\circ} \mathrm{C}$ during the early Paleogene, and the $\mathrm{TEX}_{86}$ method (Schouten et al., 2002) provides evidence that the summer SST near

* Correspondence to: Dorian S. Abbot, Harvard University, 24 Oxford St, Cambridge, MA 02138, USA. E-mail: abbot@fas.harvard.edu the North Pole was as high as $23^{\circ} \mathrm{C}$ during the Paleocene/Eocene thermal maximum (PETM) $(\sim 55 \mathrm{Ma})$ and $15-18^{\circ} \mathrm{C}$ throughout the early Paleogene (Moran et al., 2006; Sluijs et al., 2006). Other data indicate that high high-latitude SSTs were accompanied by high continental temperatures. Examples of such evidence include the existence of fossils of frost-intolerant plant and animal species such as crocodilians, palm trees, cycads, and gingers in continental interiors at up to $60-70^{\circ}$ paleolatitude (Markwick, 1998; Wing and Greenwood, 1993; Greenwood and Wing, 1995). This implies that there were times when, even during winter, there were not sustained frosts at high latitudes in continental interiors. Additionally, leaf margin analysis indicates that during the Eocene ( $\sim 56$ to $\sim 34 \mathrm{Ma}$ ) the terrestrial surface temperature had an annual mean of about $10^{\circ} \mathrm{C}$ and a cold-month mean of roughly $0^{\circ} \mathrm{C}$ at a paleolatitude of about $75^{\circ}$, which is higher than modern by about $20-25^{\circ} \mathrm{C}$ and $30-40{ }^{\circ} \mathrm{C}$, respectively (Greenwood and Wing, 1995). In aggregate, these data represent strong evidence that the climate during the late Cretaceous and early Paleogene was generally warm and remarkably equable, i.e. having a low Equator to Pole temperature difference (EPTD); (the term 'equable climate' is also used by some authors to denote a low seasonal variation in temperature (e.g. Greenwood and Wing, 1995; Huber and Sloan, 1999)).

The causes of equable climates remain elusive. During the early Paleogene the continental configuration was broadly similar to that of today, although there have 
been major changes since the Cretaceous. The atmospheric $\mathrm{CO}_{2}$ concentration may have been higher than today, although indirect measurements can only constrain the $\mathrm{CO}_{2}$ to between 400 and $4000 \mathrm{ppm}$ during the early Paleogene (Pearson and Palmer, 2000; Pagani et al., 2005). One approach to understanding equable climate dynamics is to analyze the results of sophisticated primitive-equation global climate models run with boundary conditions chosen to correspond with those believed to have prevailed during the late Cretaceous or early Paleogene and increased greenhouse gas (GHG) concentrations. Studies using atmospheric general circulation models (GCMs), whether coupled to a mixed-layer ocean (Sloan and Rea, 1995; Otto-Bliesner and Upchurch, 1997; Upchurch et al., 1998; Shellito et al., 2003) or to a full ocean GCM (Bush and Philander, 1997; Huber and Sloan, 2001) have consistently yielded the important result that these models are unable to produce a climate consistent with available proxy data. In particular, the extreme polar warmth and moderate equatorial temperatures that define equable climates have escaped simulation. Shellito et al. (2003), for example, achieved a simulation relatively close to proxy data by running an atmospheric model coupled to a slab ocean at a $\mathrm{CO}_{2}$ concentration of $2000 \mathrm{ppm}$. Still, in their simulation, the cold-month mean temperatures are as low as $-14^{\circ} \mathrm{C}$ at $70^{\circ} \mathrm{N}$, the Arctic annual mean temperature is $1{ }^{\circ} \mathrm{C}$, and the tropical temperatures increase by $5{ }^{\circ} \mathrm{C}$, all of which may be at odds with proxy data, although it is possible that biases in these data are responsible for this discrepancy. If the proxy data reflect reality, GCMs do not seem to provide accurate simulations upon extrapolation to vastly different boundary conditions and GHG forcings, even though they do reasonably well at simulating the current climate. As Huber and Sloan (2001) note, there may be some mechanism that 'maintains warm poles without warming the tropics' that operated in nature during periods of equable climate, but is missing from even the most sophisticated climate models.

A multitude of hypotheses have been proposed for the missing mechanism that would explain equable climates. Most focus on a combination of increased GHG concentrations and increased meridional heat transport, either by the atmosphere (Lindzen and Farrell, 1980; Farrell, 1990; Norris et al., 2002; Pierrehumbert, 2002) or by the ocean (Brass et al., 1982; Emanuel, 2002; Hotinski and Toggweiler, 2003). A third class concentrates on feedbacks that could affect the local high-latitude heat balance and leverage increases in the high-latitude temperature under increased GHG concentrations (Sloan et al., 1992; Kirk-Davidoff et al., 2002). We will give special attention below to the recent hypotheses involving tropical cyclones and ocean heat transport (OHT) (Emanuel, 2002) and polar stratospheric clouds (PSCs) (Sloan et al., 1992; Kirk-Davidoff et al., 2002).

Emanuel (2002) argued that increased oceanic mixing by tropical cyclones could drive a stronger oceanic meridional overturning circulation and increase the meridional OHT enough to reduce the EPTD. Korty et al. (2007) showed that increasing the tropical diffusion coefficient in an ocean GCM, even by an order of magnitude, does not significantly alter the OHT poleward of $40^{\circ}$. However, increasing the tropical diffusion does increase vertical mixing of cool abyssal water with tropical surface water and does increase low latitude OHT. So an increased level of tropical cyclones during equable climates could represent a mechanism to keep tropical surface temperatures low even at greatly increased GHG levels.

Sloan et al. (1992) speculated that more extensive wetlands led to a greatly increased atmospheric methane concentration during the Eocene, which they argued could cause increased levels of winter PSCs. The greenhouse effect of these PSCs could produce marked high-latitude surface warming during winter. By imposing optically thick winter PSCs in a GCM, Sloan and Pollard (1998) and Peters and Sloan (2000) estimated that this effect could produce a maximum winter surface warming of about $20^{\circ} \mathrm{C}$ in some local high-latitude areas. KirkDavidoff et al. (2002) criticized this work on the grounds that there is no evidence for high methane concentrations throughout the late Cretaceous and early Paleogene. They instead proposed a positive feedback mechanism by which changes in EPTD could be greatly enhanced through a complex pathway leading to changes in PSCs. A crucial aspect of the Kirk-Davidoff et al. (2002) mechanism, that the winter polar stratosphere cool if the EPTD is reduced, results from the linear relationship between stratospheric overturning circulation and the EPTD that they enforce by fiat in their model. However, using an atmospheric GCM (AGCM) modified to provide greatly increased vertical resolution in the stratosphere, Korty and Emanuel (2007) argued that energy carried into the stratosphere by higher wavenumbers prevents significant decreases in the stratospheric circulation and winter stratospheric temperatures under a large weakening of the EPTD. Although increased levels of PSCs could potentially represent part of the solution to the equable climates problem, it remains unclear whether there is a physically consistent mechanism to explain their presence.

We wish to pursue the idea of a cloud radiative feedback causing high-latitude warming in an equable climate, but focus on convective clouds instead of PSCs. The low-altitude stratus clouds that prevail at high latitudes have a large and negative cloud radiative forcing (CRF) (Kyle et al., 1991; Hartmann et al., 1992; Klein and Hartmann, 1993), while clouds associated with convection have a nearly zero CRF in the Tropics (Ramanathan et al., 1989; Harrison et al., 1990) and could potentially have a positive CRF at high latitudes under lower solar insolation. This allows the possibility of a positive feedback on surface temperatures upon the initiation of convection. Specifically, if the extratropical surface temperature were to increase enough to initiate strong convection, the resulting change from low to high clouds and from negative to neutral or positive CRF could further warm the surface, leading to more atmospheric convection and hence to a positive feedback. We propose 
that this feedback could take part in maintaining warm mid and high latitudes and a low EPTD.

Some AGCM simulations of equable climates show high-latitude convection (see section 6) and changes in CRF represent the largest source of uncertainty in GCM climate change predictions (Cess et al., 1990, 1996; Soden and Held, 2006). We believe that these factors allow for an exquisite opportunity to use a relatively simple model that can be easily run for a wide range of climate regimes to test the feasibility of a highlatitude convective cloud feedback as an explanation for the low EPTD of equable climates. We have constructed such a simple model. Given the model's simplicity, we emphasize in the strongest terms that our purpose is not a quantitative solution of the equable climate puzzle. All we set out to do is make the case that the positive feedback due to convection and high clouds should be an important part of the discussion of equable climate dynamics.

Our model is a zonally-averaged two-level model of the atmosphere in which we attempt to capture the main effects of water vapour and clouds on climate, although we neglect much of the detailed physics. We have made many assumptions, which are of varying validity. Among our more questionable assumptions is the very geometry of our model. We assume that we can provide reasonable analogues to processes such as convection using a model with only two vertical levels and that we can capture the main effects of the complex threedimensional motion of air caused by baroclinic eddies through simple parametrizations in a zonally averaged model. We acknowledge that such an approach may be problematic and try to account for some of its more egregious drawbacks. That said, significant progress has been made in climate research using atmospheric models with two vertical layers (e.g. Phillips, 1956; Held and Suarez, 1978; Held, 2000; Holton, 1992) and zonally averaged models (e.g. Budyko, 1969; Sellers, 1969; North, 1975; Held and Hou, 1980; North et al., 1981; Yao and Stone, 1987; Stone and Yao, 1987, 1990; Farrell, 1990; Sokolov and Stone, 1998; Shell and Somerville, 2005). Furthermore, like similar idealized studies of equable climates before ours (e.g. Farrell, 1990), we force our model with annual average short-wave (SW) radiation as a first step, in spite of the importance of seasonality for equable climates. We emphasize that we ask of our model only that it be a source of ideas to be later tested using fuller models and that it offer a semi-quantitative method of evaluating these ideas, not that it provide a realistic simulation of all aspects of climate.

This paper is laid out as follows. We give a brief description of the model in section 2. Section 3 contains the results for the model run with 3 and 30 vertical columns $\left(30^{\circ}\right.$ and $3^{\circ}$ meridional resolution, respectively). We use an idealized model of an atmospheric column to understand some of our results in section 4 . We analyze the sensitivity of our results to parameter changes in section 5. We discuss the relation of our work to existing and future GCM experiments in section 6 and to proxy data for tropical SSTs in section 7. We conclude in section 8 . The appendix contains a full description of the model.

\section{Model}

We offer only a brief overview of the model here. We encourage readers interested in model details to consult the appendix.

The model is two-dimensional, in height and latitude (Figure 1). It uses pressure coordinates in the vertical direction and spherical coordinates in the meridional direction. The meridional extent of the model is one hemisphere. It contains $J M A X$ atmospheric columns, where $J M A X$ is either 3 or 30 in the runs described here. Nearly all model parameters retain their values as the meridional resolution is changed (Tables A.I and A.II). Each column consists of two vertical levels - a boundary layer chosen to be between 900 and $1000 \mathrm{mb}$, and a free troposphere between 200 and $900 \mathrm{mb}$. We calculate dry static energy, $D S E$, and specific humidity, $q$, prognostically in the centre of each level. Energy and moisture are conserved in the model. Zonal mean velocities, which are calculated by solving the zonally averaged nonlinear primitive equations, advect $D S E$ and $q$. Parametrized baroclinic eddies diffuse $D S E, q$, and zonal momentum with a diffusivity that is dependent

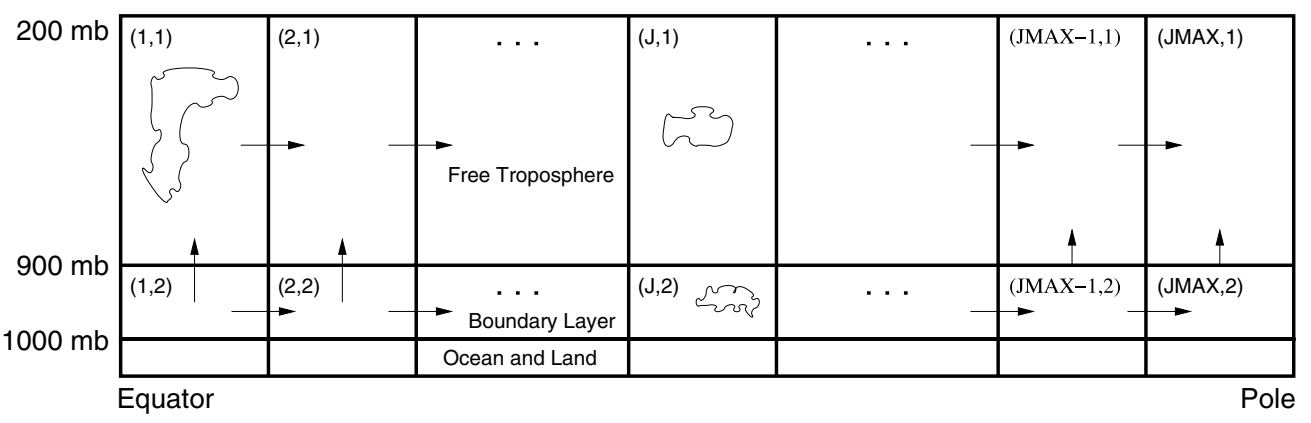

Figure 1. A diagram of the atmospheric box model. JMAX is the total number of columns, which are oriented meridionally. The upper level represents the free troposphere and the lower level represents the boundary layer. The surface consists of land and a mixed-layer ocean with a specified ocean heat transport. Arrows represent transport of moisture and DSE by both advection and baroclinic eddies. Arrows point in the direction taken to be positive, not necessarily in the direction of transport when the model is run. 
on the meridional gradient of boundary layer DSE (Stone, 1972). This parametrization does not allow upgradient eddy momentum mixing, which may reduce the realism of our simulation. Annual mean SW radiation (North, 1975) drives the model. The long-wave (LW) radiation scheme includes an explicit calculation of level emissivities as a function of water vapour, carbon dioxide, and cloud fraction (Sasamori, 1968; Lunkeit et al., 2005). The radiation scheme contains a third level above the centre of the upper level to simulate the effects of high clouds.

We parametrize convection as a vertical mixing of DSE and moisture between the two vertical layers, both of which are conserved during this mixing. We calculate convective and stratiform clouds diagnostically as a function of the strength of convective mixing and the relative humidity, respectively (Xu and Krueger, 1991; Slingo and Slingo, 1991). These clouds interact with both LW and SW radiation. Precipitation occurs if the relative humidity in any box exceeds a critical value. The lower surface of the model consists of a mixedlayer ocean with a specified OHT and a simple land surface. The land fraction, $\mathrm{frac}_{\text {land }}$, is fixed at 0.3 for all latitudes. Specific heat and moisture are exchanged with the surface using standard bulk aerodynamic formulae. Figure 2 shows processes that occur within a column of the model.

Figure 3 contains results of a 'present climate' model run with 30 columns at a $\mathrm{CO}_{2}$ of $280 \mathrm{ppm}$ and with the albedo of both land and ocean specified to increase

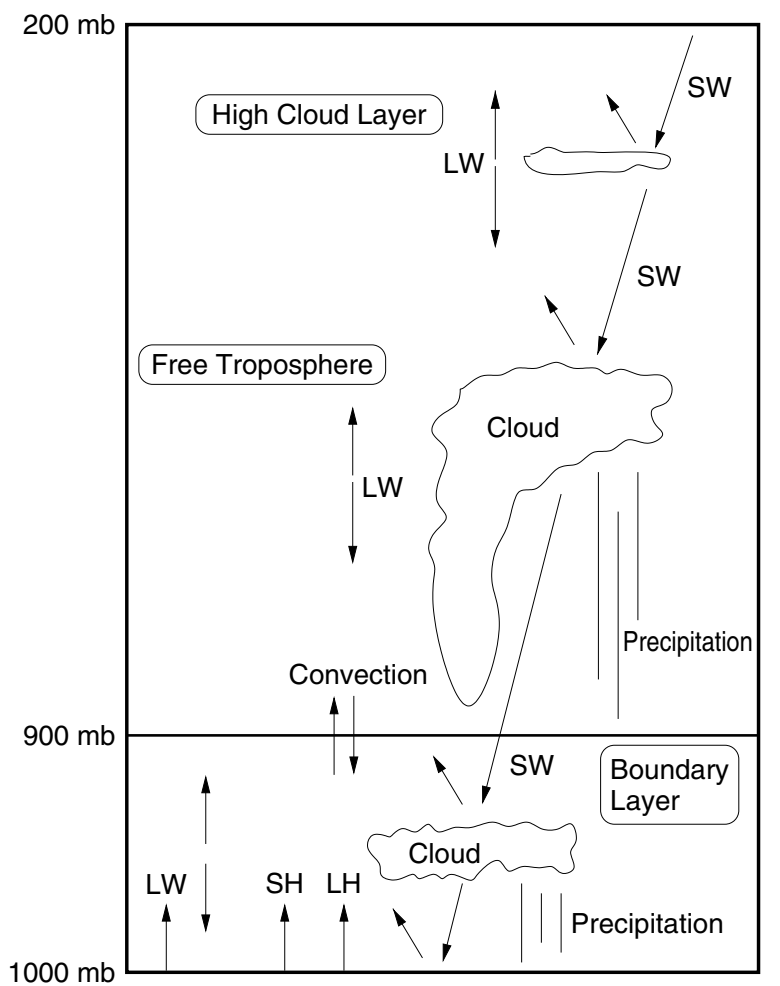

Figure 2. A diagram of single-column processes in the model. $\mathrm{SW}=$ short-wave radiation, $\mathrm{LW}=$ long-wave radiation, $\mathrm{LH}=$ latent heat flux, $\mathrm{SH}=$ sensible heat flux. linearly from their standard value at $60^{\circ}$ to 0.7 at the pole. This increased high-latitude albedo is a crude approximation of the effect of ice in the modern climate. We do not include the ice albedo parametrization in the runs we present in section 3. The model yields reasonable correspondence with modern climatology. We note in particular the similarity between Figure 3(i) and the observed annual average CRF (e.g. Figure 2 of Kyle et al., 1991). The model simulates the near-cancellation between the large and opposing cloud LW and SW forcings in regions of tropical convection (Ramanathan et al., 1989; Harrison et al., 1990) especially well. The only major qualitative difference between observed and modelled CRF is that the transition from neutral tropical CRF to strongly negative midlatitude CRF is sharper in our model, since the model switches from convective to stratiform clouds sharply. The similarity of modelled and observed CRF is important for this work since the CRF plays a central role in our mechanism. However, due to the model's simplicity, exact correspondence with modern climatology for all output should be neither expected nor required of it - the model is a conceptual tool. The model could be tuned so that the displayed output more closely approximates modern climatology, but such a tuning would be misleading since there would certainly be other aspects of the model that would not be in agreement with modern climatology. Furthermore, the results we present in section 3 are not sensitive to important parameter choices (section 5). Finally, we note that we cannot validate much of our high- $\mathrm{CO}_{2}$ model output because corresponding data from the late Cretaceous and early Paleogene do not exist, e.g. CRF.

\section{Results}

\subsection{3 columns}

For illustrative purposes, we first describe our model run with 3 columns. At this resolution the latitude ranges of the columns are $0-30^{\circ}, 30-60^{\circ}$, and $60-90^{\circ}$. Throughout this section what we refer to as the EPTD is formally the difference between the boundary-layer temperature of the $60-90^{\circ}$ column and the $0-30^{\circ}$ column.

We propose that the onset of strong convection at mid and high latitudes could lead to changes in cloud and water vapour distribution and consequently atmospheric radiative properties that could result in a positive feedback on surface temperature. Central to our arguments are the high albedo of low-altitude clouds and the greenhouse effect of high-altitude clouds (appendices A.5 and A.7), which allow the CRF to change from strongly negative to slightly positive when convection switches on in a column and high clouds are created there. Since an increase in CRF results in surface warming, this leads to a positive feedback on surface temperature as convection is enabled, which helps to sustain mid- and high-latitude convection and a lower EPTD.

This convective cloud feedback allows two distinct climate modes when the model is run with 3 columns. In 

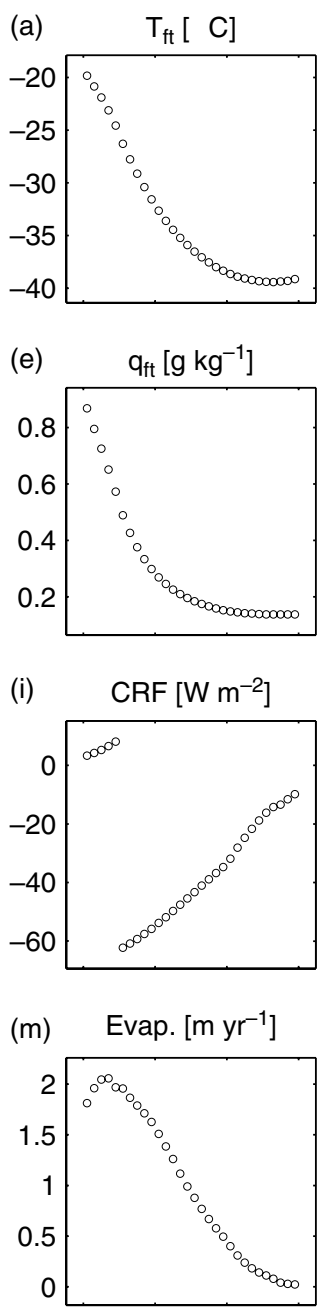

(q) $\quad \mathrm{F}_{\text {avg-le }}[\mathrm{PW}]$

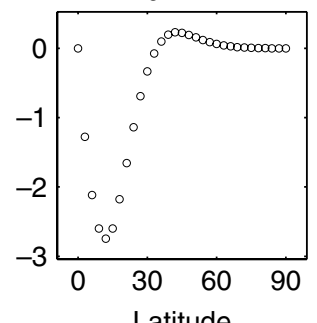

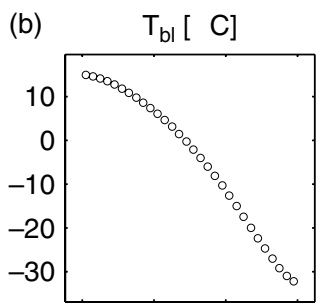
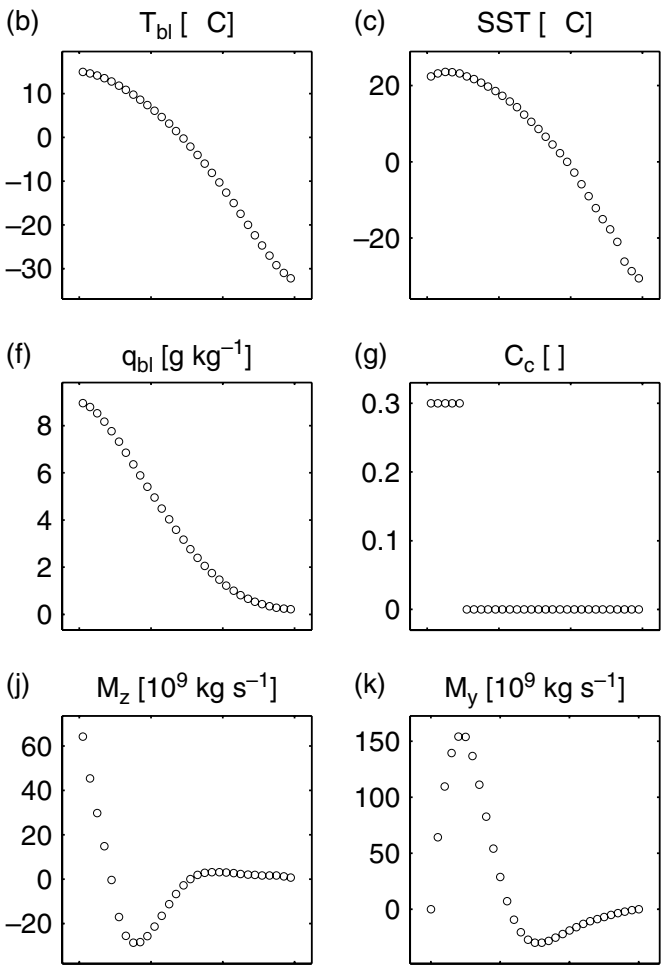

(n) $\quad \mathrm{F}_{\text {eddy-dse }}[\mathrm{PW}]$

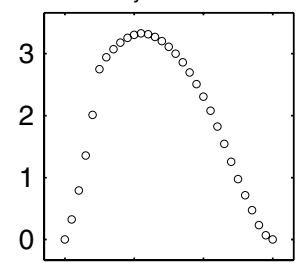

(r) $\mathrm{OHT}[\mathrm{PW}]$

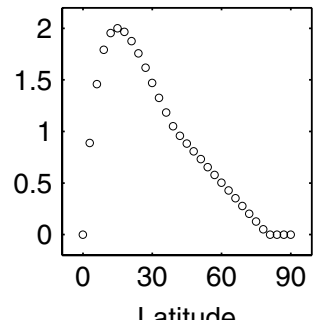

(o) $\quad \mathrm{F}_{\text {eddy-le }}[\mathrm{PW}]$

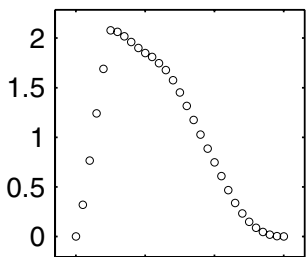

(s)

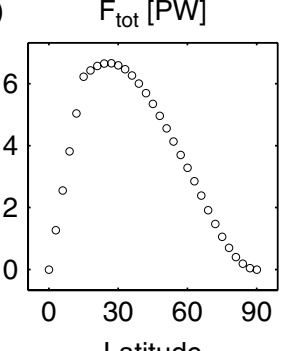

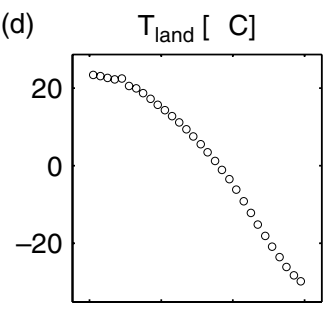

(h)

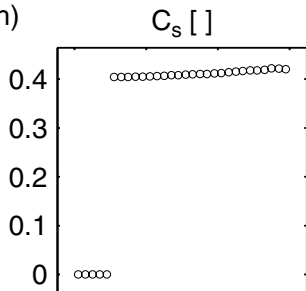

(l)

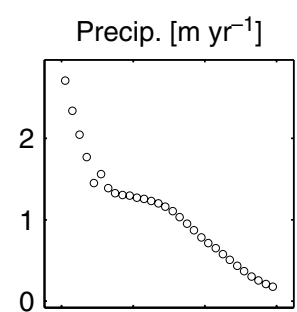

(p)

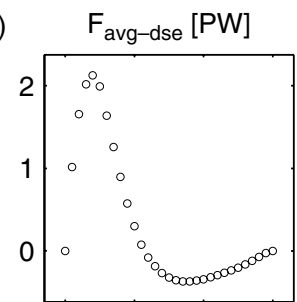

(t)

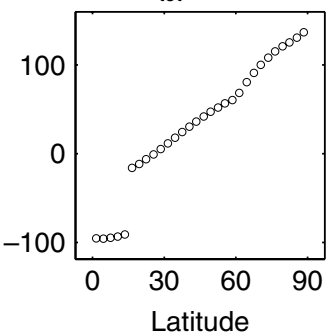

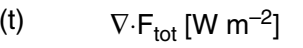

Figure 3. Steady-state model output as a function of latitude when the model is run with 30 columns ( $3^{\circ}$ latitude meridional resolution), a $\mathrm{CO}_{2}$ of $280 \mathrm{ppm}$, and the albedo of both land and ocean increasing linearly from their standard value at $60^{\circ}$ to 0.7 at the Pole. (a) $T_{\mathrm{ft}}$, free tropospheric temperature, (b) $T_{\mathrm{bl}}$, boundary-layer temperature, (c) SST, sea surface temperature, (d) $T_{\text {land }}$, land temperature, (e) $q_{\mathrm{ft}}$, free tropospheric specific humidity, (f) $q_{\mathrm{bl}}$, boundary-layer specific humidity, (g) $C_{\mathrm{c}}$, convective cloud fraction, (h) $C_{\mathrm{s}}$, boundary-layer stratiform cloud fraction, (i) CRF, cloud radiative forcing, (j) $M_{z}$, vertical mass flux, (k) $M_{y}$, meridional mass flux in the upper layer, (l) Precip, precipitation, (m) Evap, total

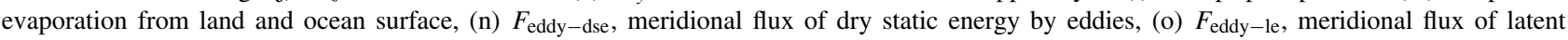
energy by eddies, (p) $F_{\text {avg-dse }}$, meridional flux of dry static energy by average circulation, (q) $F_{\text {eddy-le, }}$, meridional flux of latent energy by average circulation, (r) OHT, ocean heat transport, $\left(1 \mathrm{PW}=10^{15} \mathrm{~W}\right)$, (s) $F_{\text {tot }}$, total (atmosphere+ocean) meridional heat flux, and (t) $\nabla \cdot F_{\text {tot }}$, convergence of the total meridional heat flux.

the first mode, which is the only one present at low $\mathrm{CO}_{2}$ and which we will henceforth refer to as MODE1, only the southern column convects and the EPTD is relatively high. Other climate characteristics are generally similar to those of the modern climate. In MODE2, which is the only mode present at high $\mathrm{CO}_{2}$, convection occurs in the northern as well as in the southern column and a reduced
EPTD results. The alteration of northern CRF caused by northern convection in MODE2 allows the column to stay continually destabilized and convecting. Strong convection does not occur in the middle column in either mode because there is subsidence there (Appendix A.6).

Some of the differences between MODE1 and MODE2 can be seen in Figure 4, which shows some model 
output as a function of $\mathrm{CO}_{2}$. To generate Figure 4 we first calculated the MODE1 and MODE2 solutions by running the model to steady state under atmospheric $\mathrm{CO}_{2}$ concentrations of 200 and $6000 \mathrm{ppm}$, respectively. We then initialized the model with the MODE1 solution and ran the model to steady state at atmospheric $\mathrm{CO}_{2}$ concentrations ranging from 200 to $6000 \mathrm{ppm}$ (circles in Figure 4). Next, we initialized the model with the MODE2 solution and ran the model to steady state for the same $\mathrm{CO}_{2}$ range ( $\times$ symbols in Figure 4). The figure shows that at $1500 \mathrm{ppm}$ and below, only MODE1 is stable. (Here we use 'stable' in the dynamical systems sense, i.e. an equilibrium state is stable if a system returns to it after small perturbations away from it. We will subsequently use 'stable' in association with atmospheric column stability as well, i.e. a column is convectively stable if convection is not occurring in that column. To avoid confusion, we will qualify stability in the convective sense with some reference to convection.) At 1600 to $4900 \mathrm{ppm}$, both MODE1 and MODE2 are stable, although MODE2 is not stable even at $\mathrm{CO}_{2}=$ $10000 \mathrm{ppm}$ when the surface albedo is increased to account for ice at high latitudes, as in section 2. At $5000 \mathrm{ppm}$ and above, only MODE2 is stable. When the $\mathrm{CO}_{2}$ is slowly increased and then decreased, the model follows a hysteresis cycle.

Figure 4(a) shows the difference between the boundary-layer temperature in the equatorial column and the polar column, i.e. the 3-column EPTD. The EPTD decreases as $\mathrm{CO}_{2}$ increases mostly because the moist lapse rate feedback (section 4 ) in the $0-30^{\circ}$ column reduces increases in surface temperature with $\mathrm{CO}_{2}$ in that column relative to the $60-90^{\circ}$ column, which at low $\mathrm{CO}_{2}$ is not constrained to the moist adiabatic lapse rate since it is not convecting. When both modes exist, the EPTD is lower in MODE2 by up to $6.5^{\circ} \mathrm{C}$ (Figure 4(b)) because of a change in local heat balance in the poleward column. In MODE1 the $60-90^{\circ}$ column is stable to convection and has no convective clouds, while in MODE2 it is convecting and has convective clouds (Figure 4(c)). The increase in CRF (Figure 4(d)) caused by this difference in cloud type causes the reduction of the EPTD in MODE2 relative to MODE1, despite a decrease in meridional heat transport in MODE2 (Table I). The increase in CRF is caused by both an increase in absorbed SW and a reduction in OLR. The convective clouds reduce the OLR because they emit from a higher altitude and therefore a lower temperature. Their presence also reduces the EPTD, and therefore the atmospheric meridional heat transport, further reducing the OLR in the polar box. The increase in absorbed SW as the convective clouds form is due to a reduction of the total cloud albedo by about 0.05 as the convective clouds form (Table A.I). This is a reasonable decrease in cloud albedo for a region changing from low clouds to thick convective high clouds (Figure 19 of Hartmann et al., 1992). If, as Abbot and Tziperman (2008) find in a model with a full seasonal cycle, the convective cloud feedback is most active in the winter when incoming SW is lowest, then we may be overestimating the SW CRF in the convective regime and underestimating the warming potential of the convective cloud feedback. However, given that we do not include a seasonal cycle in this model, we feel it is appropriate to err on the side of caution. We used parameters that lead to

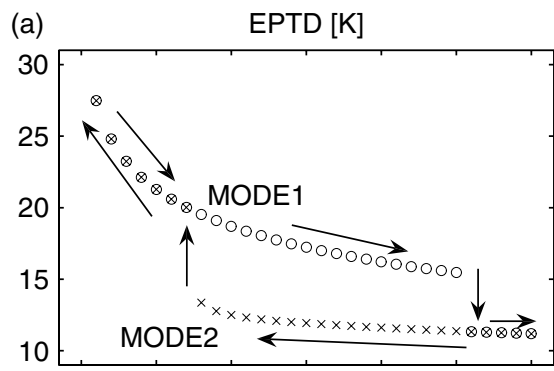

(b)

$\Delta \mathrm{EPTD}[\mathrm{K}]$
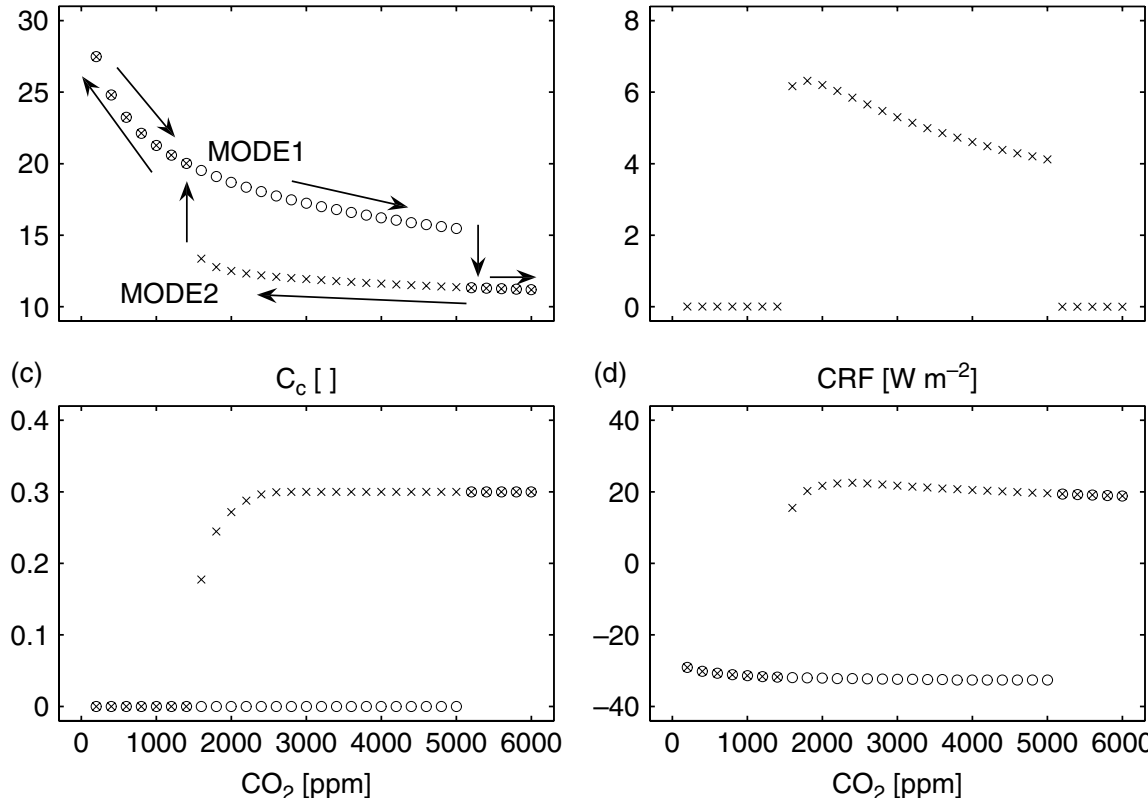

(d)

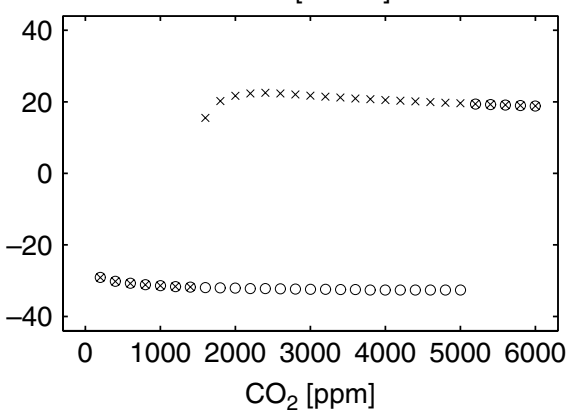

Figure 4. Selected steady-state model output for the 3-column model at different atmospheric $\mathrm{CO}_{2}$ concentrations. At each $\mathrm{CO}_{2}$ level, the model is initialized from both MODE1 (。) and MODE2 ( $\times$ ). The variables plotted are (a) Equator to Pole temperature difference (EPTD), (b) difference in EPTD between the MODE1 solution and the MODE2 solution, (c) convective cloud fraction in the $60-90^{\circ}$ column, and (d) cloud radiative forcing (CRF) in the $60-90^{\circ}$ column. MODE1 and MODE2 are labelled in (a). Arrows in (a) indicate the path the model would take if the $\mathrm{CO}_{2}$ were slowly increased then decreased. 
a present-day-like climatology at present-day forcings, as described in section 2, to generate Figure 4 (Table A.I). Reasonable variation of model parameters may lead to a change in the position of the bifurcation points that demarcate the three regions of model behaviour (MODE1 only, both modes, and MODE2 only), but the basic results are robust - there are two climatic states, one of which has a large EPTD and does not have strong convection in the poleward column (MODE1) and one of which has a low EPTD and does have strong convection in the poleward column (MODE2); the former state is stable at low $\mathrm{CO}_{2}$ levels, the latter is stable at high $\mathrm{CO}_{2}$ levels, and both are stable at intermediate $\mathrm{CO}_{2}$ levels.

The convective cloud feedback can be triggered and multiple climate states exist when parameters other than $\mathrm{CO}_{2}$ are varied. All that is necessary for the mechanism to function is for the high-latitude boundarylayer temperature to be increased enough to initiate convection there, at which point the positive feedback leads to much greater boundary-layer temperatures. For example, this can be done by increasing the specified OHT across $60^{\circ}$ (not shown).

We now proceed to the 30-column model, for which the meridional resolution is $3^{\circ}$. The results of the 30 column model confirm those discussed above and add some important perspective on the robustness of different aspects of the proposed mechanism. We have retained the 3-column model results for several reasons. First, this model shows the simplest set of physics which can reproduce the proposed convective cloud feedback. In particular, it shows that detailed momentum dynamics, which are

Table I. Temperature and heat balance for the $60-90^{\circ}$ column when the model is run with 3 columns at $\mathrm{CO}_{2}=2000 \mathrm{ppm}$, for both MODE1 and MODE2.

\begin{tabular}{lccc}
\hline Diagnostic & Unit & MODE1 & MODE2 \\
\hline$E P T D$ & ${ }^{\circ} \mathrm{C}$ & +18.7 & +12.5 \\
$T_{\text {bl }}^{3}$ & ${ }^{\circ} \mathrm{C}$ & +4.5 & +12.5 \\
$F_{\text {eddy-dse }}$ & $\mathrm{W} \mathrm{m}{ }^{-2}$ & +41.4 & +17.4 \\
$F_{\text {eddy-le }}$ & $\mathrm{W} \mathrm{m}{ }^{-2}$ & +30.2 & +13.7 \\
$F_{\text {avg-dse }}$ & $\mathrm{W} \mathrm{m}^{-2}$ & -2.2 & -4.5 \\
$F_{\text {avg-le }}$ & $\mathrm{W} \mathrm{m}^{-2}$ & +15.4 & +16.9 \\
$F_{\text {tot-atm }}$ & $\mathrm{W} \mathrm{m}{ }^{-2}$ & +84.9 & +43.5 \\
$O H T$ & $\mathrm{~W} \mathrm{~m}{ }^{-2}$ & +14.7 & +14.7 \\
$S W$ & $\mathrm{~W} \mathrm{~m}{ }^{-2}$ & +148.1 & +159.2 \\
$O L R$ & $\mathrm{~W} \mathrm{~m}{ }^{-2}$ & -247.6 & -217.6 \\
\hline
\end{tabular}

The EPTD is $T_{\mathrm{bl}}^{1}-T_{\mathrm{bl}}^{3}$, where $T_{\mathrm{bl}}^{1}$ and $T_{\mathrm{bl}}^{3}$ denote the boundary-layer temperatures in the $0-30^{\circ}$ and the $60-90^{\circ}$ columns, respectively.

$F_{\text {eddy-dse }}, F_{\text {eddy-le }}, F_{\text {avg-dse }}$ and $F_{\text {avg-le }}$ are the convergences of meridional transport of dry static energy by eddies, latent energy by eddies, dry static energy by average circulation, and latent energy by average circulation, respectively, into the $60-90^{\circ}$ column. $F_{\text {tot-atm }}$ and $O H T$ are the total convergence of meridional transport of heat by the atmosphere and ocean, respectively, into the $60-90^{\circ}$ column. $F_{\text {tot-atm }}$ is the sum of $F_{\text {eddy-dse }}, F_{\text {eddy-le }}, F_{\text {avg-dse }}$, and $F_{\text {avg-le }} . S W$ and $O L R$ are the absorbed short-wave and outgoing long-wave radiation for the $60-90^{\circ}$ column. Since the model has reached steady state, $F_{\text {tot-atm, }}$, $O H T, S W$, and $O L R$ sum to zero. For the surface area poleward of $60^{\circ}, 1 \mathrm{~W} \mathrm{~m}^{-2}=3.4 \times 10^{13} \mathrm{~W}=0.034 \mathrm{PW}$. very poorly represented in the 3-column model, are not an essential element. Second, the 3-column model results show stronger hysteresis than the higher-resolution model presented in the next section. Similarly strong hysteresis is also seen in the 30 -column model is some parameter regimes we explored. The hysteresis and multiple equilibria will likely be further or even completely muted by the addition of a third dimension and the resulting synoptic-scale motions, as well as by the addition of a seasonal cycle. However, it is important to realize that the proposed convective cloud feedback results in such multiple equilibria in the absence of additional physics, as this enriches our understanding of the proposed feedback. Specifically the existence of multiple equilibria implies that the convective cloud feedback mechanism involves both an instability mechanism and important nonlinear effects. It also implies the existence of an unstable (in the dynamical system sense) steady convective-equilibrium state between the two stable ones, which would be interesting to explore in future studies. Furthermore, when sea ice is added to the dynamics, the multiple equilibria due to the proposed feedback become even stronger and more robust, as demonstrated by Abbot and Tziperman (2008) using a single-column atmospheric model. It is therefore useful to explore the 3-column multiple equilibria dynamics without sea ice for comparison as done above. The 3-column model serves to demonstrate these points, while the higher-resolution model demonstrates the perhaps less surprising result that the multiple equilibria are not expected to be robust in the presence of additional more realistic physics.

\subsection{0 columns}

We ran the 30-column model at various $\mathrm{CO}_{2}$ concentrations in the following three ways:

- Case I: With clouds fixed at the values they take when the model is run to steady state with $\mathrm{CO}_{2}=280 \mathrm{ppm}$ (circles in Figures 5 and 6). High-latitude ice albedo is not included.

- Case II: With interactive clouds initialized from the values they take when the model is run to steady state with $\mathrm{CO}_{2}=280 \mathrm{ppm}$ (diamonds in Figure 5). This is a MODE1-like initialization.

- Case III: With interactive clouds initialized from the values they take when the model is run to steady state with all atmospheric emissivities set to one $(x$ in Figures 5 and 6). This is a MODE2-like initialization.

Figure 5 shows selected model output as a function of $\mathrm{CO}_{2}$ in each case. The model solutions in Case II and Case III are similar and exhibit a greatly reduced EPTD at $\mathrm{CO}_{2}$ levels above about 400 ppm (Figure 5(a)). (The convective cloud feedback does not activate at midlatitudes in the 30-column model until $\mathrm{CO}_{2}=600-700 \mathrm{ppm}$ when the surface albedo is increased to account for ice at high latitudes, as in section 2.) As with the 3-column model, this reduction in EPTD is due to the convective cloud 

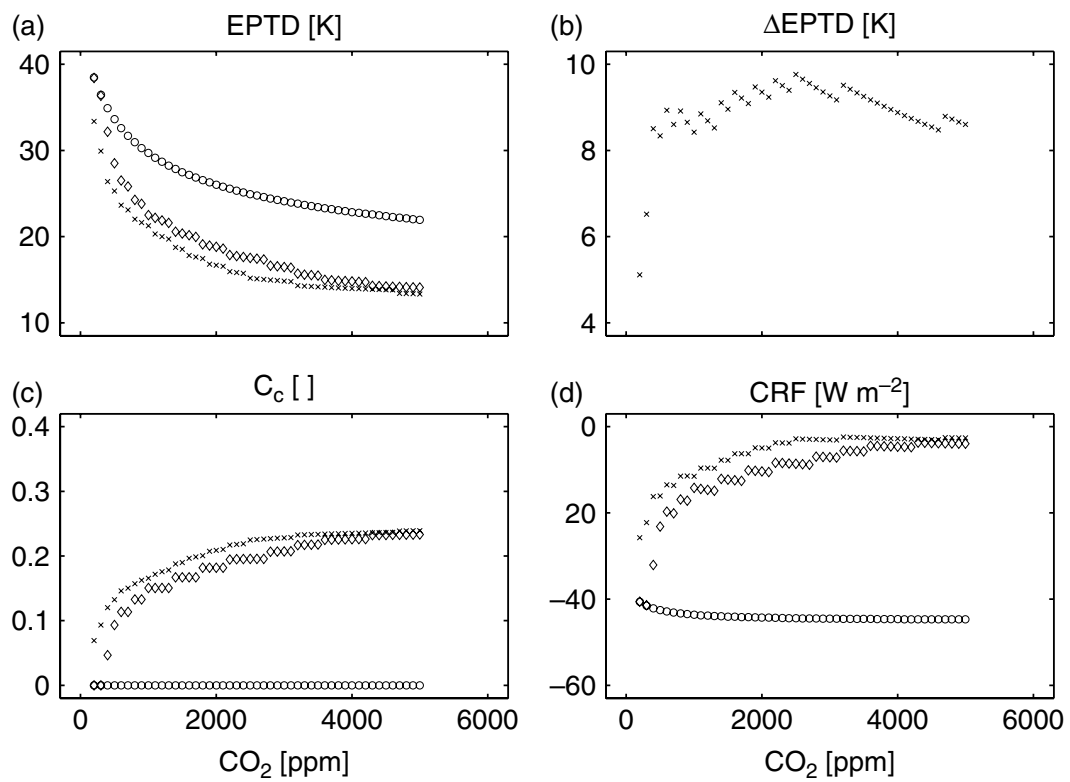

Figure 5. Selected steady-state model output for the 30-column model at different atmospheric $\mathrm{CO}_{2}$ concentrations. At each $\mathrm{CO}_{2}$ level the model is run with clouds fixed at the values they take when $\mathrm{CO}_{2}=280 \mathrm{ppm}$ (CASE I, o), with interactive clouds initialized from their values when $\mathrm{CO}_{2}=280 \mathrm{ppm}$ (CASE II, $\diamond$ ), and with interactive clouds initialized from their values with all emissivities set to one (CASE III, $\times$ ). The variables plotted are (a) Equator to Pole temperature difference (EPTD), (b) difference in EPTD between the fixed-cloud solution ( $\circ$ in other panels) and the interactive cloud solution ( $\times$ in other panels), (c) 30-90 convective cloud fraction, and (d) 30-90 cloud radiative forcing (CRF).

feedback (Figures 5(c,d)). The similarity of the solutions in Cases II and III means that the 30-column analogue of MODE1 is nearly equivalent to the 30-column analogue of MODE2. Because of this, the appropriate measure of the strength of the convective cloud feedback in the 30 column model is the difference between the EPTD in Case I, when the we fix the clouds and keep the feedback inactive, and Case III, when the feedback is fully active $(\triangle E P T D$, Figure 5(b)). Figure 5(b) shows that the convective cloud feedback leads to a reduction in the EPTD of $8-10^{\circ} \mathrm{C}$ for $\mathrm{CO}_{2}$ values ranging from 400 to 5000 ppm.

Figure 6 displays the main 30-column model variables as a function of latitude for Case I and Case III with $\mathrm{CO}_{2}=2000 \mathrm{ppm}$. The similarity between the model climate with $\mathrm{CO}_{2}=280 \mathrm{ppm}$ (Figure 3) and in Case I at $\mathrm{CO}_{2}=2000$ ppm, when the cloud feedback is disabled, (circles, Figure 6) emphasizes the magnitude of the effect the convective cloud feedback has on climate in Case III. The most striking features of the Case III climate are a reduced EPTD and an increased global mean boundary layer temperature relative to Case I (Figure 6(b)), both caused by a dramatic change from stratus to convective clouds (Figure $6(\mathrm{~g}, \mathrm{~h})$ ) and from negative to slightly positive cloud radiative forcing (Figure 6(i)) in the extratropics. Mean circulation is roughly the same in both cases (Figure 6(j,k)) and meridional heat transport is broadly reduced (Figure 6(s)), although small highlatitude increases in the convergence of meridional heat transport are important (Figure 6(t)).

In Case III, strong extratropical convection extends from 36 to $69^{\circ}$ (Figure $6(\mathrm{~g})$ ), however the increase in boundary-layer temperature over Case I extends all the way to the Pole (Figure 6(b)). As far poleward as strong convection extends, the convective cloud feedback can act directly to increase the boundary-layer temperature by altering local energy balance, as described using the 3column model of section 3.1. The 30-column model adds the important result that warming is communicated to the highest latitudes, those poleward of strong convection, by atmospheric heat transport (Figure 6(t)). Due to the reduction in meridional temperature gradient the convergence of DSE transported by eddies is decreased in Case III, but the increase in temperature causes an increase in convergence of latent energy transported by both eddies and average circulation that more than offsets this.

There are a few important new lessons to be learned from the 30-column model. First, the 30-column model confirms the importance of the convective cloud feedback in increasing high-latitude temperature. Second, the convective cloud feedback activates at a lower $\mathrm{CO}_{2}$ in the 30 -column model because the extratropics begin to convect gradually as $\mathrm{CO}_{2}$ is increased, rather than all at once. Third, the higher resolution indicates how the warming of the Pole may have occurred in moderately equable climates, specifically convection might develop in midlatitudes, and the atmosphere might transport latent heat to the highest latitudes. This may allow polar temperatures to increase even at $\mathrm{CO}_{2}$ concentrations for which convection is not active at the Poles. Fourth, the 30-column model indicates that the hysteresis seen in the 3-column model may not be robust. Although multiple steady states with and without convection still occur at intermediate $\mathrm{CO}_{2}$ concentrations with interactive clouds (Cases II and III, Figure 5), the difference between them is small and 


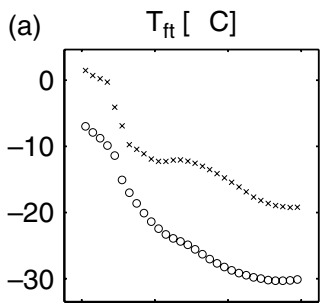

(e)

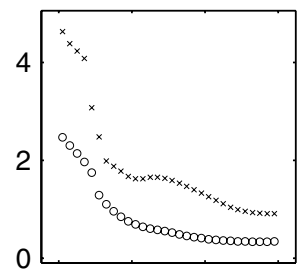

(i) $\quad \mathrm{CRF}\left[\mathrm{W} \mathrm{m}^{-2}\right]$

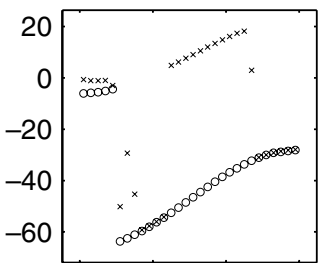

(m) Evap. $\left[\mathrm{m} \mathrm{yr}^{-1}\right]$

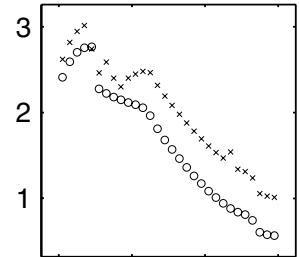

(q) $\quad F_{\text {avg-le }}[P W]$

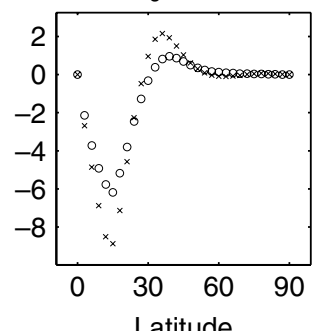

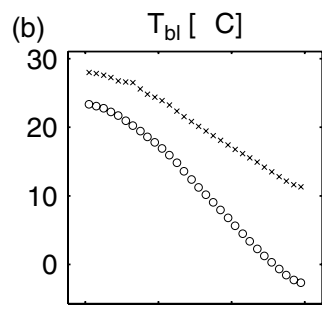

(f) $\quad q_{b l}\left[g ~ k g^{-1}\right]$
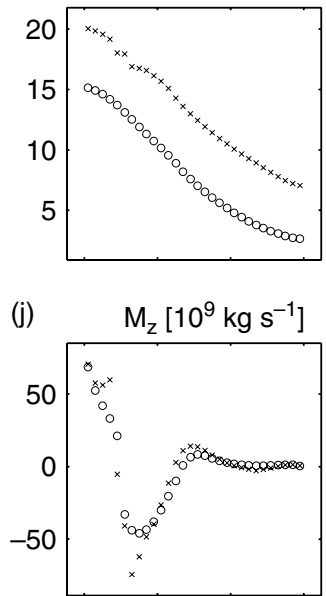

(n) $\quad \mathrm{F}_{\text {eddy-dse }}[\mathrm{PW}]$

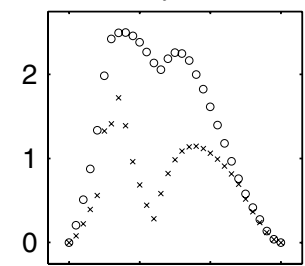

(r) $\mathrm{OHT}[\mathrm{PW}]$

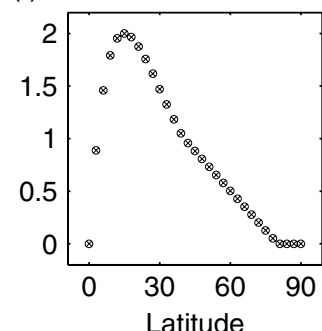

(c)

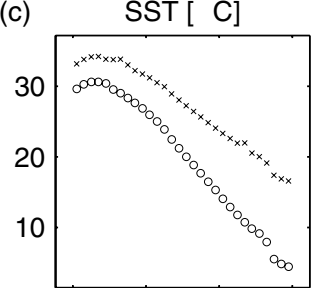

(g)

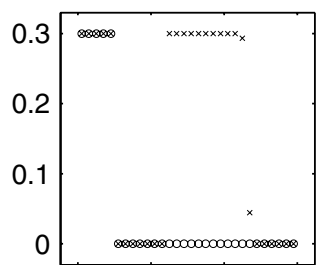

(k) $\quad \mathrm{M}_{\mathrm{y}}\left[10^{9} \mathrm{~kg} \mathrm{~s}^{-1}\right]$

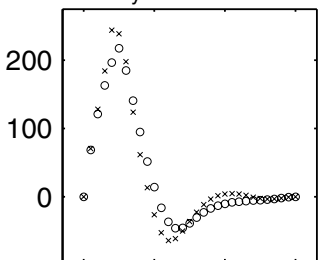

(o) $\quad F_{\text {eddy-le }}[\mathrm{PW}]$

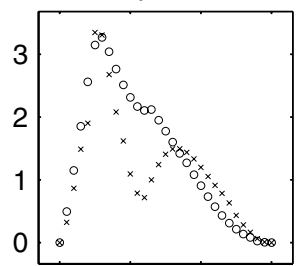

(s)

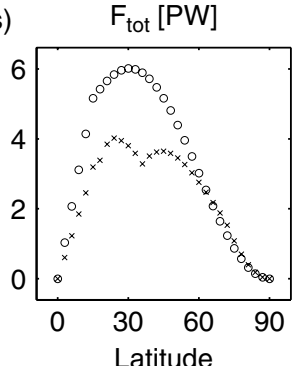

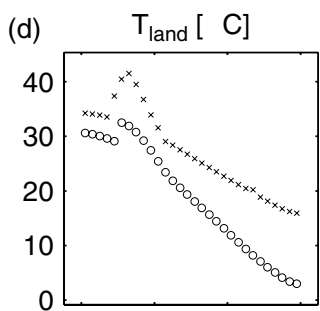

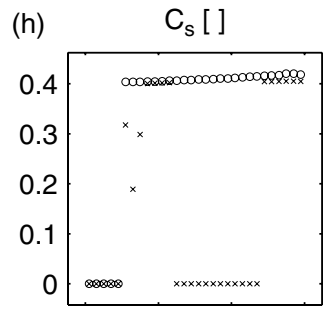

(I) Precip. $\left[\mathrm{m} \mathrm{yr}^{-1}\right]$

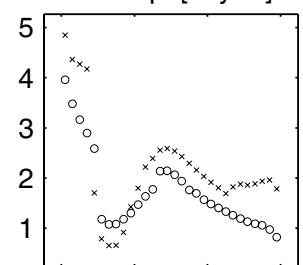

(p)

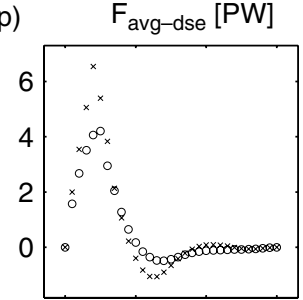

(t) $\quad \nabla \cdot \mathrm{F}_{\text {tot }}\left[\mathrm{W} \mathrm{m}^{-2}\right]$

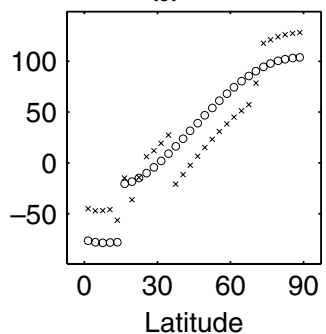

Figure 6. Steady-state model output as a function of latitude when the model is run with 30 columns ( $3^{\circ}$ latitude meridional resolution) and at a $\mathrm{CO}_{2}$ concentration of $2000 \mathrm{ppm}$. Output is displayed for the model run both with clouds fixed at the values they take when $\mathrm{CO}_{2}=280$ ppm (CASE I, 。) and with interactive clouds initialized from their values with all emissivities set to one (CASE III, $\times$ ). Panels are as in Figure 3 . The OHT is specified to be equal in both runs.

might be masked by atmospheric weather variability, were we to include such variability in this model.

Finally we note again that our model output should not be quantitatively compared to GCMs or proxy evidence. For example, the fact that more warming occurs in the northern midlatitudes in our model than in the AGCM of Shellito et al. (2003) when both are run at a $\mathrm{CO}_{2}$ concentration of $2000 \mathrm{ppm}$ is more likely the result of limitations of our model, such as an unrealistically low land fraction at these latitudes, than positive attributes. We emphasize that our objective is not to quantitatively compare our solution with the proxy record, but rather to isolate and describe a potentially important feedback in a simple model.

\section{Understanding the onset of high-latitude convection at high $\mathrm{CO}_{2}$}

Here we construct a highly idealized model of an atmospheric column and use it to heuristically explain the onset of the convective cloud feedback at high $\mathrm{CO}_{2}$. Specifically, we show that if the column is stable to 
convection, increasing the $\mathrm{CO}_{2}$ decreases the moist stability and eventually leads to convection. We supply a constant horizontal atmospheric heat transport to the idealized atmospheric column, so we neglect any dynamical feedbacks.

The idealized model contains three levels: a surface (temperature $T_{\mathrm{s}}$, emissivity $\epsilon_{\mathrm{s}}=1$ ), a boundary layer $\left(T_{2}, \epsilon_{2}\right)$, and a free troposphere $\left(T_{1}, \epsilon_{1}\right)$. We assume that the surface emissivity is one and do not account for atmospheric SW absorption. We assume a fixed atmospheric heat transport, $F_{\mathrm{a}}$, into the free tropospheric layer. A turbulent flux, $F_{\mathrm{t}}$, transports heat from the surface to the boundary layer and a convective flux, $F_{\mathrm{c}}$, transports heat from the boundary layer to the free troposphere. Heat balance for the surface, boundary layer, and free troposphere, respectively, leads to the diagnostic equations

$$
\begin{array}{r}
S(1-\alpha)+\epsilon_{2} \sigma T_{2}^{4}+\epsilon_{1}\left(1-\epsilon_{2}\right) \sigma T_{1}^{4}-\sigma T_{\mathrm{s}}^{4}-F_{\mathrm{t}}=0, \\
F_{\mathrm{t}}+\epsilon_{2} \sigma T_{\mathrm{s}}^{4}+\epsilon_{2} \epsilon_{1} \sigma T_{1}^{4}-2 \epsilon_{2} \sigma T_{2}^{4}-F_{\mathrm{c}}=0, \\
F_{\mathrm{a}}+F_{\mathrm{c}}+\epsilon_{1}\left(1-\epsilon_{2}\right) \sigma T_{\mathrm{s}}^{4}+\epsilon_{1} \epsilon_{2} \sigma T_{2}^{4}-2 \epsilon_{1} \sigma T_{1}^{4}=0,
\end{array}
$$

where $S$ is the top of the atmosphere SW, $\alpha$ is the total albedo and $\sigma$ is the Stefan-Boltzmann constant. We choose $F_{\mathrm{t}}$ to enforce a constant temperature difference $(\Delta T)$ between the surface and the boundary layer,

$$
T_{\mathrm{s}}=T_{2}+\Delta T \text {. }
$$

Let the moist static energy in the boundary layer (defined in Appendix A.6) be $M S E_{2}$ and the saturation moist static energy in the free tropospheric layer be $M S E_{1}^{*}$. We choose $F_{\mathrm{c}}$ to enforce the moist stability criticality $\left(M S E_{2} \leq M S E_{1}^{*}\right)$, so $F_{\mathrm{c}}=0$ if $M S E_{2}<M S E_{1}^{*}$ and $F_{\mathrm{c}}$ only becomes non-zero to prevent $M S E_{2}$ from exceeding $M S E_{1}^{*}$. To calculate $M S E_{2}$ and $M S E_{1}^{*}$, we assume a constant boundary-layer relative humidity $\left(\mathrm{RH}_{2}\right)$ and constant layer heights $\left(z_{1}\right.$ and $\left.z_{2}\right)$.

We model changes in $\mathrm{CO}_{2}$ by changing both $\epsilon_{1}$ and $\epsilon_{2}$ by the same amount (let $\epsilon=\epsilon_{1}=\epsilon_{2}$ ). Results are qualitatively similar regardless of how we increase $\epsilon_{1}$ and $\epsilon_{2}$. At low $\epsilon, M S E_{2}<M S E_{1}^{*}$, the model does not convect, and in the upper layer there is a balance between $F_{\mathrm{a}}$ and LW radiation terms. Increases in the optical depth of the atmosphere $(\epsilon)$ lead to larger changes in $T_{2}$ than $T_{1}$ (Figure 7(a,b)), also (Weaver and Ramanathan, 1995). The resulting increase in $\left(M S E_{2}-\right.$ $M S E_{1}^{*}$ ) (Figure 7(c,d)) is leveraged by boundary-layer moisture increasing more than free tropospheric saturation moisture because $T_{2}>T_{1}$ (Figure $7(\mathrm{e}, \mathrm{f})$ ) and because of the Clausius-Clapeyron equation. This continual destabilization of the column with respect to convection eventually causes the column to convect, at $\epsilon \approx 0.85$ in Figure 7 , which causes a kink in the plots in Figure 7 and a major change in model behaviour. Once the column is convecting, $M S E_{2}$ is constrained to equal $M S E_{1}^{*}$, so both must increase at the same rate as $\epsilon$ is increased. Since $T_{2}>T_{1}$ the moisture term in
$M S E_{2}$ (Figure 7(f)) increases faster than the saturation moisture term in $M S E_{1}^{*}$ (Figure 7(e)). Consequently the free tropospheric temperature $T_{1}$ increases more than the boundary-layer temperature $T_{2}$ and the lapse rate decreases (Figure 7(b)) as $\epsilon$ increases; this is known as the moist lapse rate feedback.

This simple model elucidates the physics leading to the onset of mid- and high-latitude convection in our more detailed models. As $\mathrm{CO}_{2}$ increases in an atmospheric column that is stable to convection, the boundary-layer temperature increases at least as much as the free tropospheric temperature. Because the boundary layer is warmer, the Clausius-Clapeyron relation dictates that the moisture content increases more there than in the free troposphere. The resulting decrease in the convective stability $\left(M S E_{1}^{*}-M S E_{2}\right)$ destabilizes the air column and eventually leads to convection.

\section{Sensitivity tests}

To build confidence in the results of section 3, we
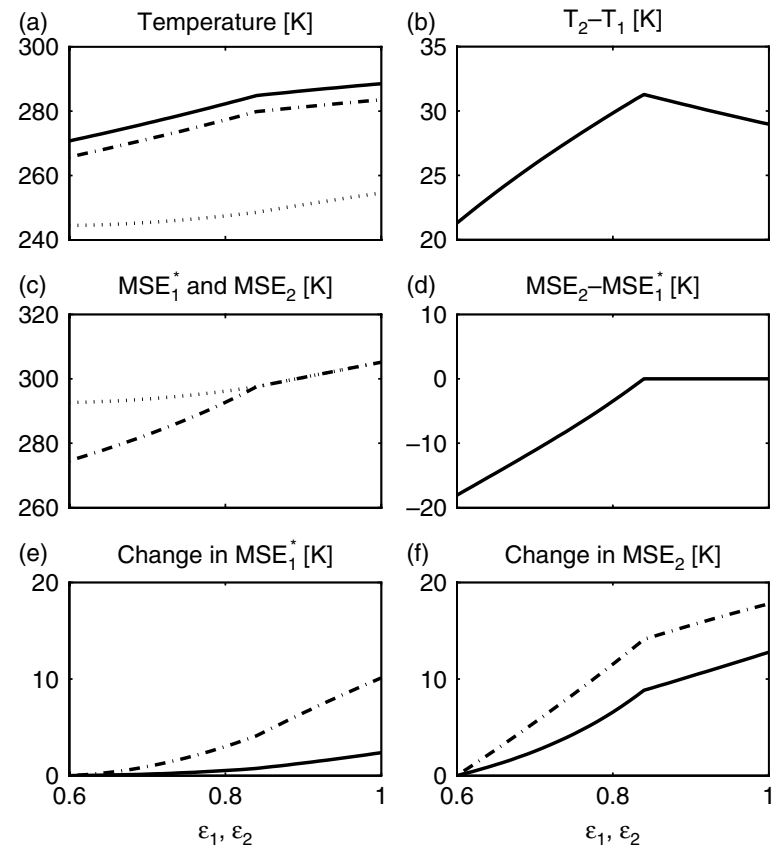

Figure 7. Equilibrium results for a 2-level atmospheric column idealized model (section 4) as a function of the specified level emissivities $\left(\epsilon_{1}\right.$ and $\epsilon_{2}$ ), where $\epsilon_{1}$ and $\epsilon_{2}$ are varied together. $S=250 \mathrm{~W} \mathrm{~m}^{-2}, \alpha=0.2$, $F_{a}=80 \mathrm{~W} \mathrm{~m}{ }^{-2}, \Delta T=5 \mathrm{~K}, z_{1}=4.8 \mathrm{~km}, z_{2}=410 \mathrm{~m}, R H_{2}=0.85$ (section 4). These parameter choices are a rough approximation of modern conditions at $60^{\circ} . z_{1}$ and $z_{2}$ correspond to pressures of $950 \mathrm{mb}$ and $550 \mathrm{mb}$, respectively, if a scale height of $8 \mathrm{~km}$ is assumed. Panels are: (a) surface temperature (solid line), boundary-layer temperature (dash-dotted) and free tropospheric temperature (dotted), (b) boundary-layer temperature minus free tropospheric temperature, i.e. the temperature lapse rate, (c) boundary-layer moist static energy (dash-dotted) and free tropospheric saturation moist static energy (dotted), (d) boundary-layer moist static energy minus free tropospheric saturation moist static energy, (e) change (from lowest value of $\epsilon_{1}$ and $\epsilon_{2}$ ) in temperature (dash-dotted) and moisture (solid) contributions to free tropospheric saturation moist static energy, and (f) change in temperature (dash-dotted) and moisture (solid) contributions to boundary-layer moist static energy. 
investigate the effects of varying important cloud and convection parameters over large ranges in the 30-column model. We establish the limits of the parameter range in which our results apply and find that our results are robust to large perturbations of important model parameters.

We quantify the effect of the convective cloud feedback for a set of parameters as the difference between the EPTD in Case I and the EPTD in Case III with $\mathrm{CO}_{2}=$ $2000 \mathrm{ppm}\left(\triangle E P T D_{2000}\right)$. Although this $\mathrm{CO}_{2}$ choice is arbitrary, it allows uniform comparison.

The convective cloud feedback involves both a reduction in the downwelling SW reflected by clouds and an increase in the upwelling LW trapped by clouds, which combine to lead to an increase in the CRF, as convective clouds form (Table I). When a parameter is altered that plays a role in setting the change in CRF as convection switches on, it affects $\triangle E P T D_{2000}$. For example increases (decreases) in the albedo of high clouds and upper-level clouds, both of which are caused by convection in this model, decrease (increase) $\triangle E P T D_{2000}$ (Figure $8(\mathrm{a}, \mathrm{c})$ ), while changes in the lower-level cloud albedo have the opposite effect (Figure 8(b)). Increasing (decreasing) the maximum convective cloud fraction is more complex because doing so simultaneously increases the upper-level emissivity and albedo, however the former effect dominates over the latter in determining $\triangle E P T D_{2000}$ (Figure $8(\mathrm{~d})$ ). Since low clouds produce only a small LW forcing, changing the maximum stratiform cloud fraction has a similar effect on $\triangle E P T D_{2000}$ as changing the low-cloud albedo (Figure 8(e)). In these experiments, the convective cloud feedback is only eliminated at $\mathrm{CO}_{2}=2000 \mathrm{ppm}\left(\triangle E P T D_{2000}=0\right)$ when the low-cloud albedo or cloud fraction is increased so much that the feedback is only active at $\mathrm{CO}_{2}>$ 2000 ppm.

Remarkably, the convective cloud feedback remains
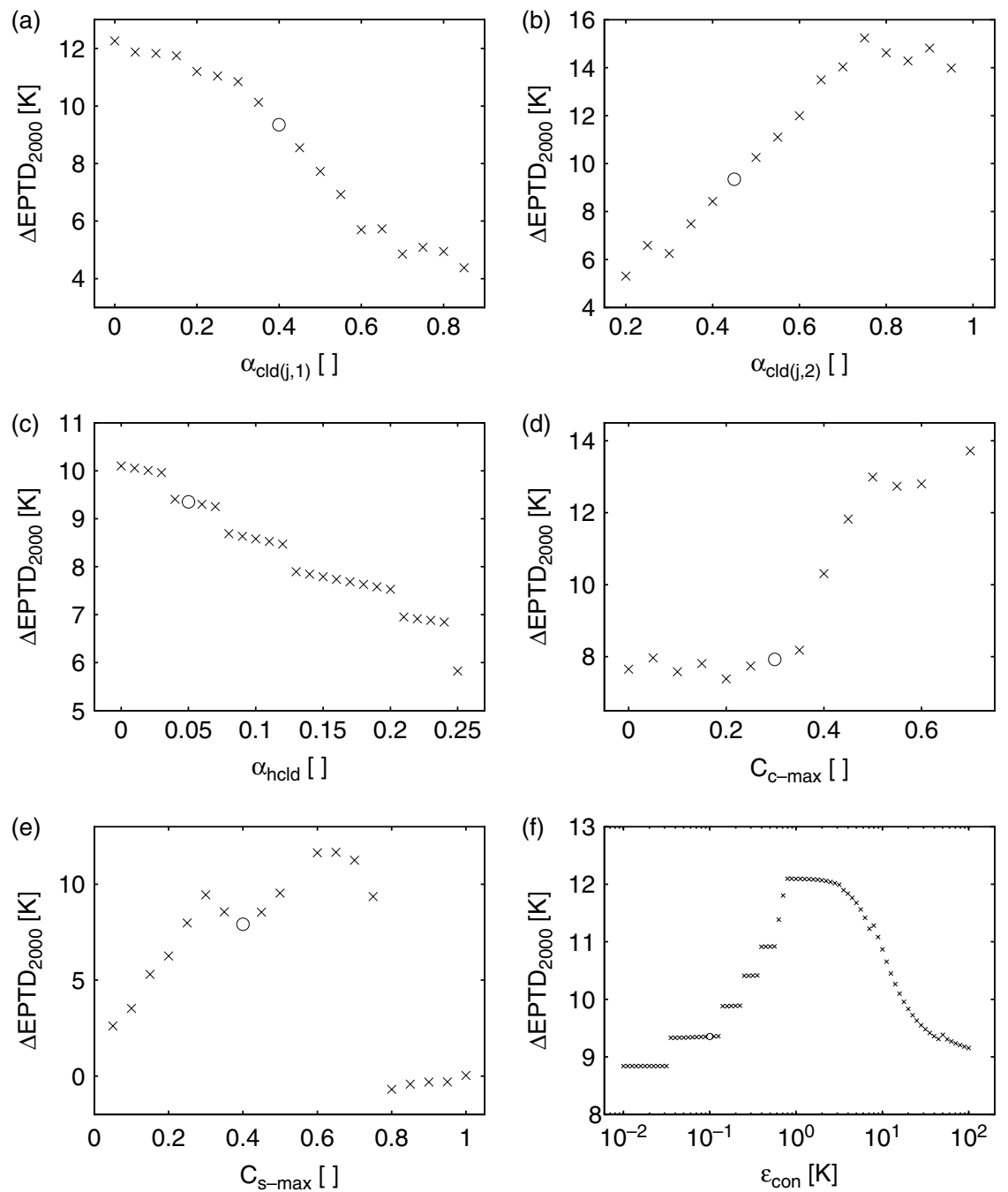

Figure 8. Sensitivity analysis: The difference between the EPTD in Case I and the EPTD in Case III with $\mathrm{CO}_{2}=2000 \mathrm{ppm}\left(\triangle E P T D_{2000}\right)$, plotted as important model parameters are varied in the 30-column model. When a parameter is varied, all other parameters retain their values given in Table A.I. Circles represent standard parameter choices (Table A.I). The varied parameters are: (a) Upper-level cloud albedo. The model does not converge to a physical solution in CASE III for $\alpha_{\operatorname{cld}(j, 1)} \geq 0.9$. (b) Lower-level cloud albedo. The model does not converge to a physical solution in CASE III for $\alpha_{\mathrm{cld}(j, 2)} \leq 0.15$. (c) High cloud albedo. (d) Maximum convective cloud fraction. The model does not converge to a physical solution in CASE III for $C_{\mathrm{c}-\max }=0.65$ and for $C_{\mathrm{c}-\max } \geq 0.75$. (e) Maximum stratiform cloud fraction. The model does not converge to a physical solution in CASE III for $C_{\mathrm{s}-\max }=0.0$ and for $C_{\mathrm{s}-\max }=0.55$. (f) Thickness of the convective switch. 
strong as we vary $\epsilon_{\text {con, }}$, the parameter controlling the scale of the convective switch, over four orders of magnitude (Figure 8(f)). The convective cloud feedback mechanism functions even when $\epsilon_{\text {con }}$ is so large that convection and convective clouds are nearly linear in convective stability, instead of switch-like. For $\epsilon_{\text {con }} \lesssim$ $1{ }^{\circ} \mathrm{C}$, increasing (decreasing) $\epsilon_{\text {con }}$ allows successively more columns to convect in CASE III, producing steplike increases (decreases) in $\triangle E P T D_{2000}$. For $\epsilon_{\text {con }} \gtrsim 1{ }^{\circ} \mathrm{C}$, increasing (decreasing) $\epsilon_{\text {con }}$ causes convecting columns to convect less strongly, and so decreases (increases) $\triangle E P T D_{2000}$.

Here we have shown that our results are robust to large changes in important cloud and convection parameters. While developing the model we performed another set of sensitivity experiments in which we increased and decreased nearly all model parameters by $25 \%$ and found that our preliminary results were robust to these changes.

\section{Discussion: The convective cloud feedback and GCMs}

It seems that the proposed convective cloud feedback mechanism is sufficiently simple and robust that it should also be seen in at least some GCM simulations of equable climate. If a model has significant deep convective activity, it should produce high clouds and associated positive CRF, as well as some LW warming due to enhanced water vapour content. Indeed, there is AGCM evidence (Huber and Sloan, 1999) that winter convection might occur over high-latitude oceans if SSTs are kept high enough to eliminate sea ice. The above paper only briefly mentions that such high-latitude convection is present, but does not discuss its role in producing high clouds and the effect of a radiative feedback on interactive surface temperatures.

We cannot conclusively determine whether other equable climate GCM simulations see such high-latitude convection, and if not why, but we offer some speculations here. The difficulty with discussing some of the published GCM runs is that they have not analyzed convection and radiation feedbacks as proposed here in most cases, so the available information is limited. It is quite possible that some of these runs did show at least some parts of our proposed high-latitude convective cloud feedback. We hope that the present paper raises the awareness to this feedback so that it can be examined in future GCM studies.

Korty and Emanuel (2007) found moist lapse rates year-round throughout the extratropics when they fixed surface meridional temperature gradients to be low in an AGCM, providing indirect evidence of high-latitude convective activity. Furthermore, Abbot and Tziperman (2008) used the NCAR single-column model with stateof-the-art atmospheric physics and a mixed-layer ocean to show that when there is no sea ice at high latitudes, high clouds and water vapour caused by winter convection exert a strong positive radiative forcing on the surface that could keep winter sea ice from forming.
Shellito et al. (2003) ran an AGCM coupled to a slab ocean at a $\mathrm{CO}_{2}$ concentration of $2000 \mathrm{ppm}$, and obtained high temperatures at high latitudes relatively close to the proxy data. The largest warming they see is during winter in the nearly ice-free Arctic, which they attribute to the sea ice albedo feedback. Given that SW radiation is reduced or zero during winter in the Arctic, the sea ice insulating feedback and the convective cloud feedback proposed here may represent more plausible causes of this warming. Their annual mean Arctic precipitation increases by some $0.5 \mathrm{~mm} \mathrm{day}^{-1}$ when the $\mathrm{CO}_{2}$ concentration is increased from 500 to $2000 \mathrm{ppm}$, in a manner quantitatively consistent with the triggering of atmospheric convection (Abbot and Tziperman, 2008). However, they briefly indicate increased large-scale precipitation at high latitudes rather than convective precipitation, although the results shown in the paper do not enable us to judge conclusively the existence of our proposed feedback in their run.

The fact that not all GCM simulations of equable climate find high-latitude convection could be due to several factors. The first, relevant to GCMs with an active sea ice component, is based on the finding of Abbot and Tziperman (2008) of enhanced multiple equilibria due to the interaction of proposed convection cloud feedback and sea ice in a full-physics single-column model. If this is indicative of the behaviour of 3D GCMs, it is possible that the GCMs only see the ice equilibria, but have not explored the parameter regime sufficiently to see the no-ice equilibria due to the computational cost of running these models. A second factor, relevant also to atmosphere-only GCMs, is the possibility that the $\mathrm{CO}_{2}$ concentration, which is highly uncertain during periods of equable climate, was not high enough in these runs. The precise $\mathrm{CO}_{2}$ concentration at which the Arctic, for example, becomes free of sea ice, deep atmospheric convection is initiated and our feedback is triggered, may vary between different GCMs. This critical $\mathrm{CO}_{2}$ value may depend on the ocean meridional heat transport and on convection, cloud, sea ice thermodynamics and sea ice albedo parametrizations, all of which have sufficient uncertainty to collectively result in a different switching point of this feedback. Given the logarithmic dependence of the radiative forcing of $\mathrm{CO}_{2}$ and the uncertainty in the true climate sensitivity to $\mathrm{CO}_{2}$, one may need to try significantly higher values. Note that Shellito et al. (2003) see significant warming nearly consistent with proxy observations only at $2000 \mathrm{ppm}$ with their oceanslab AGCM runs, while some other runs only used a $\mathrm{CO}_{2}$ of about 560 ppm (Huber and Sloan, 1999). A third factor explaining the absence of the proposed feedback is relevant to coupled ocean-atmosphere GCMs. Even if the atmospheric component of a coupled GCM shows convection at high $\mathrm{CO}_{2}$ values with a prescribed SST or with a mixed-layer ocean, it is possible that the coupled model could drift into a different regime with no high-latitude convection. Such a drift might occur due to inconsistencies between the meridional heat transport carried by the ocean model and the implied ocean heat 
transport expected by the atmosphere in atmosphere-only simulations. Climate drift forced the use of flux-corrected models for many years in the context of present-day climate studies, and this may still be an issue for equable climate simulations.

Because our model, like many of those used in previous theoretical studies of equable climates (e.g. Farrell, 1990; Kirk-Davidoff et al., 2002), is zonally averaged, the atmospheric state is the same over both ocean and land. This means that, when convection occurs, it occurs over both land and ocean. However, cooling and drying at the surface should inhibit land convection during winter. This calls into question the capacity of our proposed convective cloud feedback to produce continental interior winter temperatures high enough to be consistent with proxy data. However, modern observations (Harrison et al., 1990; Korty and Schneider, 2007) and a single-column modelling study (Abbot and Tziperman, 2008) suggest that over ocean the convective cloud feedback should be most active during winter. We speculate that moisture and cirrus clouds produced by strong convection over the ocean during winter could be advected over continents, where the resulting LW forcing could increase surface temperatures. This LW forcing would result directly from the clouds and water vapour advected over land, and from clouds formed as the water vapour condensed over land.

The high cirrus cloud lifetime of a few days may suffice to create a non-negligible radiative effect over the continents. Atmospheric eddies tend to destroy cirrus clouds and dry the atmosphere. This drying occurs due to the repeated upward and downward motions of air parcels induced by the passing eddies, causing condensation and precipitation. The eddy drying process should be less effective in an equable climate where the meridional temperature gradient is smaller and therefore the eddy activity weaker. As a result the advection of water vapour and cloud water into continental interiors may be more efficient during equable climates.

We can think of three reasons why such a process has not shown up in GCM simulations, which seem often to suffer from too low continental interior temperatures. First, many of the atmospheric models used in the past for equable climate simulations used diagnostic cloud water parametrizations rather than including horizontal cloud water advection explicitly. Second, the relatively low vertical resolution used by many climate GCMs can significantly bias the calculated vertical motions due to eddy activity (K. Emanuel, personal communication), and possibly amplify the drying effect of eddies. Both effects may significantly reduce the effect of advected water vapour and clouds on continental interiors in GCM simulations. This suggests the need to use models of higher vertical resolution, prognostic cloud water, and perhaps even prognostic cloud fraction parametrization (Tiedtke, 1993; Anderson et al., 2004) for equable climate simulations. Third, even AGCMs that produce sufficiently high high-latitude temperatures under high $\mathrm{CO}_{2}$, tend to produce a too high EPTD (Shellito et al., 2003). As a result, the eddy field may not weaken sufficiently in these simulations, and the eddy drying effect may inhibit the advection of clouds and moisture over the continents. These suggestions are all highly speculative, and we readily admit that our proposed mechanism, like many other equable climate mechanisms offered before, may not explain the warm continental interiors.

We conclude this section by noting that some elements of the convective feedback have been observed in AGCMs (Huber and Sloan, 1999; Schneider and Walker, 2006; Korty and Emanuel, 2007) and in a sophisticated, but isolated, single-column atmospheric model (Abbot and Tziperman, 2008). However, the full convective cloud feedback has not yet been observed in a coupled GCM. Although the specific reasons for this discrepancy remain unclear, potential causes are many. In particular, it is possible that the proposed feedback is active in at least some equable climate runs, but that it has not been explicitly documented and analyzed. We feel that such previous and new GCM simulations need to be reexamined in view of the proposed mechanism and that this may contribute to our understanding of the convective cloud feedback mechanism and GCM simulations of equable climates in general.

\section{Further discussion: Tropical SSTs}

An important piece of the equable climate puzzle is the consistent paleoclimatic evidence that tropical SSTs from the late Cretaceous and early Paleogene were not as high relative to modern climate as were polar surface temperatures. In our model (Case III), tropical SSTs are $31-32{ }^{\circ} \mathrm{C}$ at $\mathrm{CO}_{2}=500 \mathrm{ppm}$ (not shown) and $33-34{ }^{\circ} \mathrm{C}$ at $\mathrm{CO}_{2}=$ $2000 \mathrm{ppm}$ (Figure 6(c)) and the model produces tropical SSTs of $22.5-24^{\circ} \mathrm{C}$ for $\mathrm{CO}_{2}=280 \mathrm{ppm}$ (Figure 3(c)) and $24.5-26^{\circ} \mathrm{C}$ for $\mathrm{CO}_{2}=370 \mathrm{ppm}$ (not shown). This corresponds to a raising of tropical SSTs, from 'modern' to 'equable', of $5-11.5^{\circ} \mathrm{C}$. Estimates of ancient tropical SSTs using the $\delta^{18} \mathrm{O}$ of oxygen in the shells of planktonic Foraminifera have recently been revised upward because of the failure of previous studies to properly account for diagenetic effects on the Foraminifera and surface seawater $\delta^{18} \mathrm{O}$ gradients. Modern estimates based on $\delta^{18} \mathrm{O}$ measurements are that, during the late Cretaceous and early Paleogene, tropical SSTs were 'at least $28-32^{\circ} \mathrm{C}$ ' (Pearson et al., 2001), 33-34 ${ }^{\circ} \mathrm{C}$ (Norris et al., 2002), and $32-33{ }^{\circ} \mathrm{C}$ (Roche et al., 2006). In addition Foraminiferal $\mathrm{Mg} / \mathrm{Ca}$ ratios may support tropical SSTs of up to $34^{\circ} \mathrm{C}$, although this result depends on which $\mathrm{Mg} / \mathrm{Ca}$ history is assumed (Tripati et al., 2003). Since current tropical SSTs are in the range of $24-30^{\circ} \mathrm{C}$ (Peixoto and Oort, 1992), tropical SSTs may have been 0-10 degrees higher during equable climates. So the increase in tropical SSTs in our model as the $\mathrm{CO}_{2}$ is increased and the convective cloud feedback activates in the extratropics is consistent with the higher end of corresponding data. We believe that this consistency is reasonable given the simplicity of our model. 


\section{Conclusion}

We have demonstrated the importance of a high-latitude convective cloud feedback in determining the Equator to Pole temperature difference (EPTD) in a simple model. This feedback is due to a combination of high surface temperatures favouring strong convection and the radiative properties of clouds present during strong convection favouring high surface temperatures. Low clouds have a negative cloud radiative forcing (CRF), while high clouds have a neutral or positive CRF, so if the boundary-layer temperature can be increased enough to initiate convection and generate high clouds, the above positive feedback can be activated. The feedback we describe involves convective clouds, which are mostly tropospheric, and is different from those involving PSCs (Sloan et al., 1992; Kirk-Davidoff et al., 2002). However, recent observational evidence implying moistening of the stratosphere by extratropical convection could represent a possible connection between the two ideas (Dessler and Sherwood, 2004; Hanisco et al., 2007).

At low $\mathrm{CO}_{2}$ concentrations, the model climate operates similarly to the observed climate, while at higher $\mathrm{CO}_{2}$ the model displays convection at high latitudes and a drastically reduced EPTD. At intermediate $\mathrm{CO}_{2}$ concentrations, the positive feedback leads to multiple equilibria and allows hysteresis as the $\mathrm{CO}_{2}$ is varied, but these results may not be robust given the simplicity of our model. The convection at northern latitudes is strong and tropical-like, and a distinction should be drawn between it and the convection in the midlatitudes of the modern observed climate that is associated with the storm track. It is important to note that the reduction of the EPTD is due to a re-arrangement of local heat balance at high latitudes, rather than an increase in meridional heat transport, which, in fact, decreases in our model's low EPTD solution.

We wish to propose a possible connection between the physics of our high- $\mathrm{CO}_{2}$ solution and equable climates, such as those present during the late Cretaceous period $(\sim 100$ to $\sim 65.5 \mathrm{Ma})$ and the early Paleogene period $(\sim 65.5$ to $\sim 34 \mathrm{Ma})$. The results from our model indicate that the existence of strong convection at mid and high latitudes may have contributed to the low EPTD during these warm periods. We find it encouraging that in our model the convective cloud feedback leads to a reduced EPTD for $\mathrm{CO}_{2}>600 \mathrm{ppm}$, well within the range of $\mathrm{CO}_{2}$ estimates for periods of equable climates (Pearson and Palmer, 2000; Pagani et al., 2005).

Although we have made many approximations in our simple model, we believe we have effectively used it to subject our idea to a rudimentary plausibility test. Furthermore, we think that our model could represent a useful motivation and complement to future coupled GCM runs, as envisioned by Held (2005). Overall, we hope that this paper adds the proposed feedback based on high-latitude convection and the resulting high-cloud radiative forcing to the vocabulary of equable climate research.

\section{Acknowledgements}

We are thankful for many useful conversations with John Dykema, Kerry Emanuel, Brian Farrell, Zhiming Kuang, Richard Lindzen and Dan Schrag, and for comments on an early version of this paper by Richard Lindzen and Dan Schrag. We gratefully acknowledge Chris Walker for technical assistance. We thank Adam Sobel, Rob Korty, and Richard Seager for their reviews and comments. We thank three reviewers of the Journal of the Atmospheric Sciences for their efforts and comments on an earlier draft submitted in June 2006. DA was supported by an NDSEG fellowship, which are sponsored by the U.S. Department of Defense. ET thanks the Weizmann institute for its hospitality during a sabbatical visit. This work was supported by the NSF paleoclimate program, grant ATM-0502482, and by the McDonnell foundation.

\section{Appendices: Detailed model description}

We outline the dry static energy and moisture equations in Appendix A.1 and the calculation of velocities from the primitive equations in Appendix A.2. We describe the model's grid and the calculation of advective terms in Appendix A.3 and the eddy parametrization in Appendix A.4. Appendix A.5 contains the radiation scheme. We explain the convection and precipitation schemes in Appendix A.6 and our cloud parametrization in Appendix A.7. We describe ocean and land surface properties and fluxes of sensible and latent heat from the surface in Appendix A.8.

\section{A.1. Dry static energy and moisture equations}

Dry static energy, $D S E$, is defined as the sum of the gravitational potential energy and the internal energy

$$
D S E=\phi+C_{p} T .
$$

We solve the following equations for DSE and the specific humidity, $q$ :

$$
\begin{aligned}
\frac{\partial D S E}{\partial t}= & \left(\frac{\partial D S E}{\partial t}\right)_{\mathrm{adv}}+\left(\frac{\partial D S E}{\partial t}\right)_{\text {eddy }} \\
& +\left(\frac{\partial D S E}{\partial t}\right)_{\mathrm{rad}}+\left(\frac{\partial D S E}{\partial t}\right)_{\text {sens }} \\
& +\left(\frac{\partial D S E}{\partial t}\right)_{\text {conv }}+\left(\frac{\partial D S E}{\partial t}\right)_{\text {precip }} \\
& +\left(\frac{\partial D S E}{\partial t}\right)_{\text {re-evap }}, \\
\frac{\partial q}{\partial t}= & \left(\frac{\partial q}{\partial t}\right)_{\text {adv }}+\left(\frac{\partial q}{\partial t}\right)_{\text {eddy }} \\
& +\left(\frac{\partial q}{\partial t}\right)_{\text {evap }}+\left(\frac{\partial q}{\partial t}\right)_{\text {conv }} \\
& +\left(\frac{\partial q}{\partial t}\right)_{\text {precip }}+\left(\frac{\partial q}{\partial t}\right)_{\text {re-evap }} .
\end{aligned}
$$


We describe the calculation of advective (adv) and eddy terms in Appendices A.3 and A.4, the radiation term in Appendix A.5, sensible heat (sens) and surface evaporation (evap) terms in Appendix A.8, and convection (conv), precipitation (precip), and re-evaporation (reevap) terms in Appendix A.6.

\section{A.2. Velocity scheme}

We solve the zonally averaged spherical primitive equations in pressure coordinates.

$$
\begin{aligned}
\frac{\partial u}{\partial t}= & -\frac{1}{a \cos \theta} \frac{\partial}{\partial \theta}(u v \cos \theta)+\frac{u v}{a} \tan \theta \\
& -\frac{\partial}{\partial p}(\omega u)+2 \Omega v \sin \theta \\
& +\left(\frac{\partial u}{\partial t}\right)_{\text {eddy }}-r_{\mathrm{f}} \delta_{k 2} u, \\
\frac{\partial v}{\partial t}= & -2 \Omega u \sin \theta-\frac{1}{a} \frac{\partial \phi}{\partial \theta} \\
& -r_{\mathrm{f}} \delta_{k 2} v+\widetilde{v} \frac{1}{a^{2}} \frac{\partial^{2} v}{\partial \theta^{2}}, \\
\frac{\partial \phi}{\partial p}= & \frac{1}{\rho}, \\
0= & \frac{1}{a \cos \theta} \frac{\partial}{\partial \theta}(v \cos \theta)+\frac{\partial \omega}{\partial p}, \\
p= & \rho R T
\end{aligned}
$$

Here $t$ is time, $\theta$ is the latitude, $p$ is the pressure, $u$ is the zonal velocity, $v$ is the meridional velocity, $\omega=\mathrm{d} p / \mathrm{d} t$ is the pressure velocity, $\rho$ is the air density, $R$ is the ideal gas law constant, $\Omega$ and $a$ are the Earth's rotation rate and radius, respectively, $T$ is the temperature, and $\delta_{\mathrm{ij}}$ is the Kronecker delta (subscript ${ }_{k}$ refers to vertical level, see below). The terms with $r_{\mathrm{f}}$ in Equations (A.3) and (A.4) represent friction in the boundary layer. Hydrostaticity is assumed in Equation (A.5). We will discuss the parametrization of the eddy term in Equation (A.3) in Appendix A.4. We neglect advective terms from the material derivative in Equation (A.4) because they do not enter the dominant balance. The term involving $\widetilde{v}$ in Equation (A.4) is for numerical smoothing. All quantities in Equations (A.3)-(A.6) are zonally averaged. This scheme yields a Hadley cell of reasonable magnitude and a Ferrell cell with an amplitude that is somewhat too small (Figures 3(j) and 3(k)). The simulation of the Ferrell cell in our model may suffer from the fact that eddies cannot mix momentum up-gradient in our model, as they do in nature.

\section{A.3. Grid and advective terms}

We use an Arakawa C-type grid, so DSE, $q$ and $u$ are defined on box centres while $v$ and $\omega$ are defined at box edges (Figure A.1). We label model boxes with two indices $-j$ and $k . j$ gives the meridional position and ranges from 1 in the most equatorward column to JMAX in the most poleward column. $k$ denotes vertical level and takes the value 1 in the free troposphere and 2 in the boundary layer. We split Equations (A.3) and (A.4) into their barotropic and baroclinic components and integrate the barotropic and baroclinic zonal and meridional velocities to steady state using a leapfrog scheme with a Robert filter in time. We calculate pressure velocity and geopotential diagnostically using Equations (A.5) and (A.6).

We calculate the advection and eddy tendencies for each grid box by multiplying fluxes across box interfaces, $\{F\}$, by cross-sectional areas and dividing by the box volume

$$
\begin{aligned}
\left(\frac{\partial X}{\partial t}\right)_{\text {adv or eddy }}= & \frac{F_{1} \cos \theta_{1}-F_{2} \cos \theta_{2}}{a\left(\sin \theta_{2}-\sin \theta_{1}\right)} \\
& +\frac{F_{\mathrm{t}}-F_{\mathrm{b}}}{p_{\mathrm{b}}-p_{\mathrm{t}}},
\end{aligned}
$$

where $X$ is $D S E, q$, or $u$. The subscripts 1 and 2 denote the equatorward and poleward sides of the box, respectively, and the subscripts ${ }_{t}$ and ${ }_{b}$ denote the top and bottom of the box, respectively. We calculate the fluxes, $\{F\}$, using an upwind scheme for advection and Equations (A.9)-(A.11) for eddies.

\section{A.4. Baroclinic eddy parametrization}

We simplistically parametrize the meridional transport of $D S E$, moisture and zonal momentum by baroclinic eddies as a diffusion process with a diffusion coefficient that is dependent on the boundary-layer DSE gradient and the vertical level (Stone, 1972). We assume that vertical transport by eddies acts mainly to redistribute DSE and moisture within the free troposphere and neglect transport between the boundary layer and the free troposphere. We also do not include the effect of static stability on eddies. The meridional eddy transports of DSE, $q$, and $u$ are given by

$$
\overline{v^{\prime} D S E^{\prime}}=-K_{D S E} D_{k} \frac{\partial D S E}{\partial \theta},
$$

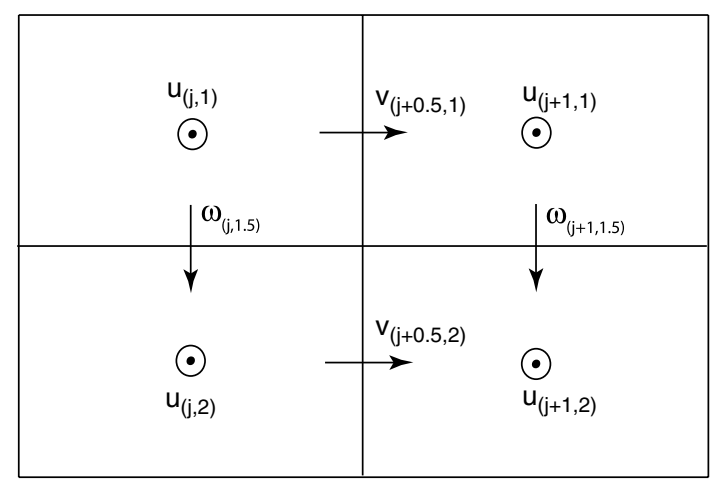

Figure A.1. A diagram of the Arakawa C-type grid used for velocity variables in the model. Arrows point in the positive direction for each velocity variable. The positive direction for zonal velocities is out of the page. Dry static energy and specific humidity are at the box centres with zonal velocity. 


$$
\begin{aligned}
& \overline{v^{\prime} q^{\prime}}=-K_{q} D_{k} \frac{\partial q}{\partial \theta}, \\
& \overline{v^{\prime} u^{\prime}}=-K_{u} D_{k} \frac{\partial u}{\partial \theta} .
\end{aligned}
$$

We choose the parameters $K_{D S E}$ and $K_{q}$ so that maximum eddy $D S E$ and latent heat energy transports for the present-day model simulation are roughly consistent with Trenberth and Stepaniak (2003) and $K_{u}$ so that the model produces a reasonable circulation (Appendix A.2). $D_{k}$ is the diffusion coefficient, given by

$$
D_{k}=C_{k}\left|\frac{\partial D S E_{2}}{\partial \theta}\right|
$$

We include $C_{k}$, the vertical dependence of the diffusion coefficient, because GCM results indicate that friction present in the boundary layer reduces baroclinic eddy transport there (Branscome et al., 1989; Stone and Yao, 1990). Following Nakamura et al. (1994), we parametrize this effect by multiplying transports by a factor of $1-\mathrm{e}^{-z / \Delta z}$ where $\Delta z \approx 450 \mathrm{~m}$, which yields $C_{1} \approx 1$ and $C_{2} \approx 0.5$ upon vertical averaging.

\section{A.5. Radiation}

We use the parametrization of North (1975) and Nakamura et al. (1994) for the meridional distribution of the mean annual SW radiation impinging on the top of the atmosphere:

$$
Q(\theta)=\frac{Q_{0}}{4}\left\{1+\frac{Q_{2}}{2}\left(3 \sin ^{2} \theta-1\right)\right\},
$$

where $Q_{0}=1365 \mathrm{~W} \mathrm{~m}^{-2}$ and $Q_{2}=-0.482$. This formula approximates the zonal and annual mean SW radiative flux to within $2 \%$. We do not include seasonal and diurnal variations in $\mathrm{SW}$ radiation.

We assume random overlap of the cloud layers for the calculation of SW radiation reaching the surface

$$
\begin{aligned}
F_{\mathrm{sw}}^{\downarrow}= & Q(\theta)\left(1-\alpha_{\mathrm{sfc}}\right)\left(1-f_{\mathrm{c}}^{1} \alpha_{\mathrm{cld}}^{1}\right) \\
& \times\left(1-f_{\mathrm{c}}^{2} \alpha_{\mathrm{cld}}^{2}\right)\left(1-f_{\mathrm{c}}^{\text {high }} \alpha_{\mathrm{cld}}^{\text {high }}\right) .
\end{aligned}
$$

Here $\alpha_{\text {sfc }}$ is the surface albedo, which takes different values over land and ocean. $f_{\mathrm{c}}^{i}$ and $f_{\mathrm{c}}^{\text {high }}$ are the cloud fractions and $\alpha_{\text {cld }}^{i}$ and $\alpha_{\text {cld }}^{\text {high }}$ are the cloud albedos. The high superscript refers to the third cloud layer, which is above the centre of the free tropospheric layer, and which we will describe below. We neglect the scattering of SW radiation by the atmosphere. We assume boundary-layer

\begin{tabular}{|c|c|c|}
\hline Parameter & Unit & Value \\
\hline$C_{\mathrm{c}-\max }$ & - & 0.30 \\
\hline$C_{\text {s-max }}$ & - & 0.40 \\
\hline$C_{\mathrm{lh}-\text { land }}$ & - & $2.0 \times 10^{-3}$ \\
\hline$C_{\mathrm{lh}-\mathrm{ocn}}$ & - & $1.0 \times 10^{-3}$ \\
\hline$C_{\text {sh-land }}$ & - & $2.0 \times 10^{-3}$ \\
\hline$C_{\mathrm{sh}-\mathrm{ocn}}$ & - & $1.0 \times 10^{-3}$ \\
\hline$C_{\text {land }}$ & $\mathrm{J} \mathrm{m}^{-3} \mathrm{~K}^{-1}$ & $2.0 \times 10^{6}$ \\
\hline$C_{\text {ocn }}$ & $\mathrm{J} \mathrm{kg}^{-1} \mathrm{~K}^{-1}$ & $4.19 \times 10^{3}$ \\
\hline$D_{\text {land }}$ & $\mathrm{m}$ & 1.0 \\
\hline$D_{\text {ocn }}$ & $\mathrm{m}$ & 1.0 \\
\hline $\mathrm{d} t$ & $\mathrm{~s}$ & 10 \\
\hline$f_{\text {evap }}$ & - & 0.5 \\
\hline$f r a c_{\text {land }}$ & - & 0.3 \\
\hline$K_{D S E}$ & $\mathrm{~m} \mathrm{~s}^{-1} \mathrm{~J}^{-1}$ & $0.8 \times 10^{9}$ \\
\hline$K_{q}$ & $\mathrm{~m} \mathrm{~s}^{-1} \mathrm{~J}^{-1}$ & $4.0 \times 10^{9}$ \\
\hline$k_{\mathrm{con}-\max }$ & $\mathrm{s}^{-1}$ & $1.0 \times 10^{-5}$ \\
\hline$M_{\min }$ & - & 0.01 \\
\hline$M_{\text {squash }}$ & $\mathrm{kg} \mathrm{s}^{-1}$ & 7.0 \\
\hline $\mathrm{OHT}_{0}$ & W & $2.0 \times 10^{15}$ \\
\hline$R H_{\text {crit }(j, 1)}$ & - & 0.6 \\
\hline$R H_{\text {crit }(j, 2)}$ & - & 0.8 \\
\hline$r_{\mathrm{f}}$ & $\mathrm{s}^{-1}$ & $2.0 \times 10^{-6}$ \\
\hline$|\mathbf{v}|$ & $\mathrm{m} \mathrm{s}^{-1}$ & 6.0 \\
\hline$\alpha_{\text {cld }}^{1}$ & - & 0.40 \\
\hline$\alpha_{\text {cld }}^{2}$ & - & 0.50 \\
\hline$\alpha_{\text {cld }}^{\text {high }}$ & - & 0.05 \\
\hline$\alpha_{\text {land }}$ & - & 0.20 \\
\hline$\alpha_{\text {ocn }}$ & - & 0.10 \\
\hline$\epsilon_{\mathrm{con}}$ & $\mathrm{K}$ & 0.1 \\
\hline$\epsilon_{r 0}$ & - & 2.5 \\
\hline$\theta_{\text {decay }}$ & degrees & 15.0 \\
\hline$\theta_{\text {lin }}$ & degrees & 40.0 \\
\hline$\theta_{\text {zero }}$ & degrees & 80.0 \\
\hline$\widetilde{v}^{210}$ & $\mathrm{~m}^{2} \mathrm{~s}^{-1}$ & $1.0 \times 10^{8}$ \\
\hline$\rho_{\mathrm{ocn}}$ & $\mathrm{kg} \mathrm{m} \mathrm{m}^{-3}$ & $1.0 \times 10^{3}$ \\
\hline$\tau_{\text {precip }}$ & $\mathrm{S}$ & 250 \\
\hline
\end{tabular}
clouds have higher albedos than free tropospheric clouds (Table A.I) (Arking, 1991; Hartmann et al., 1992; Baker, 1997). We neglect the dependence of cloud albedo on
Table A.I. Standard model parameters for both the 3- and 30-column models.

Parameter symbols are defined in the text.

solar zenith angle (Cess, 1976; Lian and Cess, 1977) and many other potentially important cloud albedo effects.

The LW radiation scheme consists of a three-layer model. The bottom two layers correspond to the model mid-box levels and have emissivities calculated as a function of water vapour and carbon dioxide mixing ratios and cloud fraction (Sasamori, 1968; Lunkeit et al., 2005). We assume that the highest cloud layer, which contains only high convective clouds, is in radiative equilibrium.

The effective path length of a gas in the atmosphere is defined as (Sasamori, 1968)

$$
l=\frac{1}{g} \int_{P_{1}}^{P_{2}} \widehat{q} \times \frac{P}{P_{s}} \mathrm{~d} P,
$$

where $\widehat{q}$ is the mixing ratio by mass of the species, e.g. $\mathrm{CO}_{2}$ or water vapour, and $P_{1}$ and $P_{2}$ are the pressure 
limits of the layer being considered. We assume the mixing ratio is constant within each box. This is a better approximation for $\mathrm{CO}_{2}$ than for water vapour, which decays rapidly with height, but we feel that even for water vapour assuming a constant mixing ratio is sufficient for the arguments we make using this model. Assuming constant mixing ratio, the relation for the effective path length can be integrated to yield

$$
l=\frac{\widehat{q}}{2 g P_{s}}\left(P_{2}^{2}-P_{1}^{2}\right)
$$

which gives the effective path length in $\mathrm{kg} \mathrm{m}^{-2}$.

We convert the water vapour path length to $\mathrm{gm} \mathrm{cm}^{-2}$ and the carbon dioxide path length to $\mathrm{cm}$ at STP (273.15 $\mathrm{K}$ and $10^{5} \mathrm{~Pa}$ ) and use the following formulae to calculate emissivities (Sasamori, 1968):

$$
\begin{aligned}
& \epsilon_{\mathrm{H}_{2} \mathrm{O}}=A_{1} \log _{10}\left(u_{\mathrm{H}_{2} \mathrm{O}}+B_{1}\right)+C_{1}, \\
& \epsilon_{\mathrm{CO}_{2}}=A_{2} \log _{10}\left(u_{\mathrm{CO}_{2}}\right)+B_{2} .
\end{aligned}
$$

Table A.II gives values of the constants.

We use the transmissivity of water vapour near the $15 \mu \mathrm{m}$ region to account for the overlap between water vapour and carbon dioxide absorption (Sasamori, 1968)

$$
\tau_{\mathrm{H}_{2} \mathrm{O}}=1.33-0.832\left(u_{\mathrm{H}_{2} \mathrm{O}}+0.0286\right)^{0.260}
$$

so that the clear-sky emissivity is given by (Sasamori, 1968)

$$
\epsilon_{\text {clear }}=\epsilon_{\mathrm{H}_{2} \mathrm{O}}+\epsilon_{\mathrm{CO}_{2}} \times \tau_{\mathrm{H}_{2} \mathrm{O}}
$$

We take the transmissivity of a layer to be the product of the clear-sky and cloud transmissivities, yielding (Lunkeit et al., 2005)

$$
\epsilon=\epsilon_{\text {clear }}+f_{\mathrm{c}} \epsilon_{\mathrm{c}}-f_{\mathrm{c}} \epsilon_{\mathrm{c}} \epsilon_{\text {clear }} .
$$

Here $f_{\mathrm{c}}$ is the cloud fraction and $\epsilon_{\mathrm{c}}$ is the emissivity of clouds, which we set to one for all cloud types.

We calculate cloud radiative forcing using the following formulae

$$
\begin{gathered}
C R F_{\mathrm{lw}}=O L R_{\mathrm{clear}}-O L R, \\
C R F_{\mathrm{sw}}=\left(F_{\mathrm{sw}}^{\downarrow}\right)-\left(F_{\mathrm{sw}}^{\downarrow}\right)_{\mathrm{clear}}, \\
C R F=C R F_{\mathrm{lw}}+C R F_{\mathrm{sw}} .
\end{gathered}
$$

Here $O L R$ is the upward LW radiation at the top of the atmosphere, $F_{\mathrm{sw}}^{\downarrow}$ is defined in Equation (A.12), and the clear subscript refers to the value of the quantity when the atmosphere is cloud-free. Since we do not include the absorption of $\mathrm{SW}$ radiation by the atmosphere, $C R F_{\mathrm{sw}}$ is the same whether it is calculated at the surface or at the top of the atmosphere. We first run the model to steady state and calculate $O L R$ and $F_{\mathrm{sw}}^{\downarrow}$. We then calculate $O L R_{\text {clear }}$ by running the LW radiation code using the steady-state temperatures and with all cloud emissivities set to zero. We calculate $\left(F_{\mathrm{sw}}^{\downarrow}\right)_{\text {clear }}$ by setting all cloud albedos to zero.

The positive LW radiative forcing of high clouds is due to the fact that they radiate at low temperatures. Cirrus and other types of clouds associated with strong convection often occur at or above the tropopause. Our highest model layer is centred at $550 \mathrm{mb}$, so the warming effect of high clouds is drastically reduced. To get a realistic LW forcing from high clouds we add a layer above the centre of the free troposphere model layer made up entirely of convective clouds (Appendix A.7). We assume that this layer is in radiative equilibrium and it only exists in the radiation scheme. It has an emissivity of $\epsilon_{\text {high }}=f_{c}^{\text {high }} \epsilon_{c}$, where $f_{c}^{\text {high }}$ is the cloud fraction in this layer, so its emissivity is zero when there is no convection (Eq. (A.25)). With this modification the cloud radiative forcing in the model is reasonable when the model is run at $\mathrm{CO}_{2}=280 \mathrm{ppm}$ and with polar ice (Figure 3). We also tried assuming an altitude of the high clouds and then calculating their temperature from the upper box temperature using the moist adiabatic lapse rate. We found that the high-cloud temperatures thus produced are similar to the high-cloud temperatures produced by assuming radiative equilibrium, both at low and high $\mathrm{CO}_{2}$. Our method has the advantage that we do not need to specify the altitude of the high clouds.

When we ran the model using the formulae from Sasamori (1968), the global mean surface temperature increased by only $0.6^{\circ} \mathrm{C}$ with 3 columns and $0.8^{\circ} \mathrm{C}$ with 30 columns in response to a doubling of atmospheric carbon dioxide from 280 to $560 \mathrm{ppm}$. These values, which are commonly referred to as the equilibrium climate sensitivity (Cubasch and Meehl, 2001), are consistent with Ohring and Adler (1978), who obtained a value of $0.5^{\circ} \mathrm{C}$ with ice held constant in a zonally averaged twolevel model with an embedded higher-resolution radiation model with a LW scheme based on Sasamori (1968). We modified the Sasamori (1968) coefficients (Table A.II) so that the equilibrium climate sensitivity is $2.5^{\circ} \mathrm{C}$ for the 3 -column model and $3.8^{\circ} \mathrm{C}$ for the 30 -column model, consistent with the range of $2.0-5.1^{\circ} \mathrm{C}$ given by the Intergovernmental Panel on Climate Change Third Assessment Report (Cubasch and Meehl, 2001). The sensitivity is larger in the 30 -column model because when $\mathrm{CO}_{2}=280 \mathrm{ppm}$ strong convection only occurs in the 30 -column model between 0 and $15^{\circ}$, whereas the entire

Table A.II. Values of parameters in this paper's LW radiation scheme compared with those of Sasamori (1968).

\begin{tabular}{lcc}
\hline Parameter & This paper & Sasamori (1968) \\
\hline$A_{1}$ & 0.50 & 0.2400 \\
$B_{1}$ & 0.77 & 0.6220 \\
$C_{1}$ & 0.01 & 0.0100 \\
$A_{2}$ & 0.20 & 0.5460 \\
$B_{2}$ & $-0.1,-0.18^{*}$ & 0.0581 \\
\hline
\end{tabular}

${ }^{*}$ For 30- and 3-column models, respectively. 
column spanning $0-30^{\circ}$ convects in the 3 -column model, allowing the moist lapse rate feedback to operate over a much larger area in the 3-column model. When we held the water vapour constant for the LW scheme, but allowed it to increase elsewhere in the model, the climate sensitivity was $1.6^{\circ} \mathrm{C}$ with 3 columns and $2.1^{\circ} \mathrm{C}$ with 30 columns, so that the water vapour feedback accounts for one third to one half of the total climate sensitivity, which is roughly consistent with the results of more complex models (Cubasch and Meehl, 2001; Colman, 2003). In all the runs described in this paragraph we held the surface albedo at a constant value of 0.7 poleward of $60^{\circ}$ (section 2 ), so there was no surface albedo feedback. The cloud feedback was negligible because the clouds only change from their MODE1 configuration under larger GHG forcings.

\section{A.6. Convection and precipitation}

The moist static energy is defined as (Emanuel, 1994)

$$
M S E=D S E+L_{v} r .
$$

Here $L_{v}$ is the latent heat of water and $r$ is the water vapour mixing ratio. The saturation MSE is calculated using the saturation mixing ratio instead of the actual mixing ratio.

We parametrize convection as a vertical mixing of $D S E$ and $q$ that activates when the boundary-layer moist static energy exceeds the free tropospheric saturation moist static energy (Raymond, 1995). We accomplish this parametrized convection using a tanh-smoothed switch, so that the convective mixing coefficient is given by

$$
\begin{aligned}
k_{\mathrm{con}}= & k_{\mathrm{con}-\min }+\frac{1}{2}\left(k_{\mathrm{con}-\max }-k_{\mathrm{con}-\min }\right) \\
& \times\left\{1+\tanh \left(\frac{M S E_{2}-M S E_{1}^{*}}{C_{\mathrm{pd}} \epsilon_{\mathrm{con}}}\right)\right\},
\end{aligned}
$$

where $k_{\text {con-min }}$ is the vertical mixing coefficient in a stable atmosphere, $k_{\text {con-max }}$ is the vertical mixing coefficient for an unstable atmosphere, and $\epsilon_{\mathrm{con}}$ sets the scale of $M S E_{2}-M S E_{1}^{*}$ over which convection turns on. DSE and water vapour are conserved during this mixing. We neglect the vertical mixing of momentum by convection.

Due to low vertical resolution, subsidence does not inhibit convection in our model as effectively as it does in the atmosphere. We therefore shut convection off when the descent mass flux exceeds $M_{\text {squash }}$. We experimented with slightly more sophisticated parametrizations, such as assuming that the descending air followed a dry adiabat and the ascending air followed a saturation moist adiabat and calculating the stability by comparing the two temperatures at some intermediate pressure, and found little difference in the results.

We assume that precipitation occurs within a box when the relative humidity exceeds a critical relative humidity,
$R H_{\text {crit }}$. When this is the case, the precipitative tendencies are

$$
\begin{aligned}
\frac{\partial q}{\partial t} & =\frac{q_{\text {crit }}-q}{\tau_{\text {precip }}}, \\
\frac{\partial D S E}{\partial t} & =-L_{v} \frac{\partial q}{\partial t} .
\end{aligned}
$$

Here $q_{\text {crit }}$ is the specific humidity corresponding to the critical relative humidity and $\tau_{\text {precip }}$ is a precipitation time-scale. A fraction, $\epsilon_{\mathrm{r}}$, of precipitation produced by convection in the upper level is re-evaporated into the lower level as it falls through it:

$$
\epsilon_{\mathrm{r}}=\epsilon_{\mathrm{r} 0}(1-R H) .
$$

A realistic value of $\epsilon_{\mathrm{r}}$ is roughly 0.1 , but in our model we choose $\epsilon_{\mathrm{r} 0}=2.5$ so that $\epsilon_{\mathrm{r}}$ is sometimes as high as 0.75 . This compensates for the tendency of the model to excessively dry the boundary layer of convecting regions, which may result from our treatment of convection with a mixing parametrization, which may not be appropriate in many circumstances. Consequently we consider the reevaporation parametrization to be part of the convection scheme itself rather than to represent the physical process of re-evaporation.

\section{A.7. Cloud parametrization}

We diagnostically calculate convective clouds as a function of convective mass flux and stratiform clouds as a function of relative humidity (Xu and Krueger, 1991).

We interpret the normalized convective mixing coefficient, which is defined as

$$
M=\frac{k_{\mathrm{con}}-k_{\mathrm{con}-\min }}{k_{\mathrm{con}-\max }-k_{\mathrm{con}-\min }},
$$

as the two-level analogue of convective mass flux. Since $k_{\text {con }}$ is a switch-like function (Equation (A.20)), $M$ is as well. We parametrize the convective cloud fraction as

$$
C_{\mathrm{c}}=C_{\mathrm{c}-\max }\left\{\frac{\log \left(M / M_{\min }\right)}{\log \left(M_{\min }\right)}\right\}^{2},
$$

where $C_{\mathrm{c}}$ is the convective cloud fraction and $C_{\mathrm{c}}=0$ if $M<M_{\min }$. We imagine modelled convective clouds as including anvil clouds spread from the site of convection.

We parametrize the stratiform cloud fraction using relative humidity

$$
C_{s}=C_{\text {s-max }}\left(\frac{R H^{\prime}-R H_{0}}{R H_{2}^{*}-R H_{0}}\right)^{2},
$$

with $C_{s}=0$ for $R H^{\prime}<R H_{0}$. Following Slingo and Slingo (1991), we reduce the relative humidity upon which stratiform clouds are calculated in regions in which there is convective cloud activity:

$$
R H^{\prime}=R H\left(1-C_{c}\right)
$$


This adjustment is based on the assumption that the air is saturated in convective clouds.

We calculate the total cloud fraction in each layer as

$$
\begin{aligned}
f_{\mathrm{c}}^{\text {high }} & =C_{\mathrm{c}}, \\
f_{\mathrm{c}}^{1} & =C_{\mathrm{c}}+C_{\mathrm{s}}^{1}, \\
f_{\mathrm{c}}^{2} & =C_{\mathrm{s}}^{2} .
\end{aligned}
$$

Here $f_{\mathrm{c}}^{\text {high }}$ is the cloud fraction in the upper cloud level (Appendix A.5), $f_{\mathrm{c}}^{1}$ is the free tropospheric cloud fraction, and $f_{\mathrm{c}}^{2}$ is the boundary layer cloud fraction. $C_{\mathrm{s}}^{k}$ are the stratiform cloud fractions in the boundary layer and free troposphere, which we calculate based on the relative humidity there.

\section{A.8. Surface temperatures and exchanges}

We use bulk aerodynamic formulae to calculate surface sensible heat and evaporative fluxes (Peixoto and Oort, 1992):

$$
\begin{gathered}
F_{\mathrm{sh}}=\rho C_{p} C_{\mathrm{sh}}|\mathbf{v}|\left(\theta_{\mathrm{s}}-\theta_{2}\right), \\
E=\rho C_{\mathrm{lh}}|\mathbf{v}|\left(q_{\mathrm{s}}^{*}-q_{2}\right) .
\end{gathered}
$$

The latent heat flux is the product of the evaporative flux and the latent heat of vaporization $\left(F_{\mathrm{lh}}=L_{v} E\right) . q_{\mathrm{s}}^{*}$ is the saturation specific humidity based on the surface temperature. $|\mathbf{v}|$ is the air speed near the surface, which we take to be a constant. $C_{\mathrm{sh}}$ and $C_{\mathrm{lh}}$ take different values over land and ocean (Table A.I). Over land we reduce the evaporative flux by multiplication by the fraction $f_{\text {evap }}$, which we set to a constant. We assume the land has no capacity to store water and we do not allow land evaporation to exceed instantaneous land precipitation.

We calculate land and sea surface temperatures prognostically. Land surface heat balance can be written

$$
\begin{gathered}
C_{\text {land }} D_{\text {land }} \frac{\partial T_{\text {land }}}{\partial t}=F_{\mathrm{sw}-\text { land }}^{\downarrow}+\epsilon_{\text {land }} F_{\text {lw }}^{\downarrow} \\
-\epsilon_{\text {land }} \sigma T_{\text {land }}^{4}-F_{\text {sh-land }}^{\uparrow}-F_{\text {lh-land }}^{\uparrow},
\end{gathered}
$$

where $T_{\text {land }}$ is the land surface temperature, $C_{\text {land }}$ is the land volume heat capacity and $D_{\text {land }}$ is the depth of soil that exchanges heat with the atmosphere. $F_{\mathrm{sw}-\text { land }}^{\downarrow}$ is given by Equation (A.12) using the land albedo. $\epsilon_{\text {land }}$ is the land emissivity, which we set to one, and $F_{\mathrm{lw}}^{\downarrow}$ is the downward LW flux of radiation due to re-emission by the atmosphere.

The ocean consists of a mixed layer of vertically uniform temperature with specified meridional ocean heat transport. Heat balance in this mixed layer can be written

$$
\begin{gathered}
C_{\mathrm{ocn}} D_{\mathrm{ocn}} \rho_{\mathrm{ocn}} \frac{\partial S S T}{\partial t}=\frac{O H T_{\mathrm{in}}-O H T_{\mathrm{out}}}{A_{\mathrm{ocn}}} \\
+F_{\mathrm{sw}-\mathrm{ocn}}^{\downarrow}+\epsilon_{\mathrm{ocn}} F_{\mathrm{lw}}^{\downarrow}-\epsilon_{\mathrm{ocn}} \sigma(S S T)^{4} \\
-F_{\mathrm{sh}-\mathrm{ocn}}^{\uparrow}-F_{\mathrm{lh}-\mathrm{ocn}}^{\uparrow} .
\end{gathered}
$$

Most of Equation (A.29) is analogous to Equation (A.28). We set $\epsilon_{\text {ocn }}$ to one. We use the mass heat capacity of water for $C_{\mathrm{ocn}}$. To decrease the time the model takes to reach steady state, we set the depth of the mixed layer, $D_{\text {ocn }}$, to $1 \mathrm{~m}$. The model produced identical steady-state results when we set $D_{\text {ocn }}$ to $50 \mathrm{~m}$ in test runs. $O H T_{\text {in }}$ and $O H T_{\text {out }}$ are the energy per unit time transported by the ocean into and out of the column being considered.

We specify the $O H T$ so that it roughly fits the presentday profile as inferred from satellite radiative data and atmospheric reanalysis data given by Trenberth and Caron (2001). The model $O H T$ as a function of latitude, $\theta$, takes the form

$$
\begin{aligned}
& \text { OHT }= \\
& \begin{cases}\left(\frac{O H T_{0}}{\mathrm{e}}\right)\left(\frac{\theta}{\theta_{\text {decay }}}\right) \mathrm{e}^{-\frac{\theta}{\theta_{\text {decay }}}} & \text { for } \theta<\theta_{\text {lin }}, \\
O H T_{\text {lin }}\left(\frac{\theta_{\text {zero }}-\theta}{\theta_{\text {zero }}-\theta_{\text {lin }}}\right) & \text { for } \theta_{\text {lin }} \leq \theta<\theta_{\text {zero }}, \\
0 & \text { for } \theta_{\text {zero }} \leq \theta .\end{cases}
\end{aligned}
$$

The linear portion of this function brings the $O H T$ to zero without causing excessive heat convergence in a poleward box. Inter-hemispheric $O H T$ is not included so the model's heat budget is closed. $O H T_{0}$ is the maximum $O H T$ and $\theta_{\text {decay }}$ gives both the location of this maximum and the decay scale at higher latitudes. $\theta_{\text {lin }}$ and $\theta_{\text {zero }}$ are the latitudes at which the $O H T$ becomes linear and zero, respectively. $O H T_{\text {lin }}$ is the $O H T$ at $\theta_{\operatorname{lin}}$ based on the lower latitude formula

$$
O H T_{\text {lin }}=\left(\frac{O H T_{0}}{\mathrm{e}}\right)\left(\frac{\theta_{\text {lin }}}{\theta_{\text {decay }}}\right) \mathrm{e}^{-\frac{\theta_{\text {lin }}}{\theta_{\text {decay }}}} .
$$

Table A.I gives $O H T$ parameter choices in the standard run and Figure 3(r) shows the resulting $O H T$ for the 30column model.

\section{References}

Abbot DS, Tziperman E. 2008. Sea ice, high-latitude convection and equable climates. Geophys. Res. Lett. in press. http://swell.eps.harvard.edu/ abbot/PAPERS/abbot-tziperman-08a. pdf

Anderson JL, Balaji V, Broccoli AJ, Cooke WF, Delworth TL, Dixon KW, Donner LJ, Dunne KA, Freidenreich SM, Garner ST, Gudgel RG, Gordon CT, Held IM, Hemler RS, Horowitz LW, Klein SA, Knutson TR, Kushner PJ, Langenhorst AR, Lau NC, Liang Z, Malyshev SL, Milly PCD, Nath MJ, Ploshay JJ, Ramaswamy V, Schwarzkopf MD, Shevliakova E, Sirutis JJ, Soden BJ, Stern WF, Thompson LA, Wilson RJ, Wittenberg AT, Wyman BL. 2004. The new GFDL global atmosphere and land model AM2-LM2: Evaluation with prescribed SST simulations. $J$. Climate 17(24): 4641-4673.

Arking A. 1991. The radiative effects of clouds and their impact on climate. Bull. Am. Meteorol. Soc. 72(6): 795-813.

Baker MB. 1997. Cloud microphysics and climate. Science 276(5315): 1072-1078.

Branscome LE, Gutowski WJ, Stewart DA. 1989. Effect of surface fluxes on the nonlinear development of baroclinic waves. J. Atmos. Sci. 46(4): 460-475.

Brass GW, Southam JR, Peterson WH. 1982. Warm saline bottom water in the ancient ocean. Nature 296: 620-623. 
Budyko MI. 1969. The effect of solar radiation variations on the climate of the earth. Tellus 21: 611-619.

Bush ABG, Philander SGH. 1997. The late Cretaceous: Simulation with a coupled atmosphere-ocean general circulation model. Paleoceanography 12(3): 495-516.

Cess RD. 1976. Climate change: Appraisal of atmospheric feedback mechanisms employing zonal climatology. J. Atmos. Sci. 33(10): $1831-1843$.

Cess RD, Potter GL, Blanchet JP, Boer GJ, Del Genio AD, Déqué M, Dymnikov V, Galin V, Gates WL, Ghan SJ, Kiehl JT, Lacis AA, Le Treut H, McAvaney BJ, Meleshko VP, Mitchell JFB, Morcrette JJ, Randall DA, Rikus L, Roeckner E, Royer JF, Schlese U, Sheinin DA, Slingo A, Sokolov AP, Taylor KE, Washington WM, Wetherald RT, Yagai I. 1990. Intercomparison and interpretation of cloud-climate feedback processes in 19 atmospheric general circulation models. J. Geophys. Res. 95: 16 601-16615.

Cess RD, Zhang MH, Ingram WJ, Potter GL, Alekseev V, Barker HW, Cohen-Solal E, Colman RA, Dazlich DA, Del Genio AD, Dix MR, Esch M, Fowler LD, Fraser JR, Galin V, Gates WL, Hack JJ, Kiehl JT, Le Treut H, Lo KK-W, McAvaney BJ, Meleshko VP, Morcrette J-J, Randall DA, Roeckner E, Royer J-F, Schlesinger ME, Sporyshev PV, Timbal B, Volodin EM, Taylor KE, Wang W, Wetherald RT. 1996. Cloud feedback in atmospheric general circulation models: an update. J. Geophys. Res. 101: 12791-12794.

Colman R. 2003. A comparison of climate feedbacks in general circulation models. Clim. Dyn. 20(7-8): 865-873.

Cubasch U, Meehl GA. 2001. Projections of future climate change. IPCC Third Assessment Report: Climate Change 2001. The scientific basis contribution of Working Group I to the Third Assessment Report of the Intergovernmental Panel on Climate Change. Houghton JT, Ding Y, Griggs D, Noguer M, van der Linden PJ, Dai X, Maskell K, Johnson CA. (eds). Cambridge University Press: UK.

Dessler AE, Sherwood SC. 2004. Effect of convection on the summertime extratropical lower stratosphere. J. Geophys. Res. 109.

Emanuel KA. 1994. Atmospheric convection. Oxford University Press: UK.

Emanuel KA. 2002. A simple model of multiple climate regimes. $J$. Geophys. Res. 107: DOI: 10.1029/2001JD001002.

Farrell BF. 1990. Equable climate dynamics. J. Atmos. Sci. 47(24): 2986-2995.

Greenwood DR, Wing SL. 1995. Eocene continental climates and latitudinal temperature gradients. Geology 23(11): 1044-1048.

Hanisco TF, Moyer EJ, Weinstock EM, St Clair JM, Sayres DS, Smith JB, Lockwood R, Anderson JG, Dessler AE, Keutsch FN, Spackman JR, Read WG, Bui TP. 2007. Observations of deep convective influence on stratospheric water vapor and its isotopic composition. Geophys. Res. Lett. 34: L04814, DOI: 10.1029/2006GL027899

Harrison EF, Minnis P, Barkstrom BR, Ramanathan V, Cess RD, Gibson GG. 1990. Seasonal variation of cloud radiative forcing derived from the earth radiation budget experiment. J. Geophys. Res. 95(D11): $18687-18703$.

Hartmann DL, Ockert-Bell ME, Michelsen ML. 1992. The effect of cloud type on Earth's energy balance: Global analysis. J. Climate 5: $1281-1304$.

Held IM. 2000. The general circulation of the atmosphere. Proc. Program in Geophysical Fluid Dynamics, Woods Hole Oceanographic Institution: Woods Hole, MA. http://gfd.whoi.edu/proceedings/ 2000/PDFvol2000.html.

Held IM. 2005. The gap between simulation and understanding in climate modeling. Bull. Am. Meteorol. Soc. 86(11): 1609-1614.

Held IM, Hou AY. 1980. Non-linear axially-symmetric circulations in a nearly inviscid atmosphere. J. Atmos. Sci. 37(3): 515-533.

Held IM, Suarez MJ. 1978. A two-level primitive equation atmospheric model designed for climatic sensitivity experiments. J. Atmos. Sci. 35: $206-229$.

Holton JR. 1992. An Introduction to Dynamic Meteorology. (3rd ed.) Academic Press.

Hotinski RM, Toggweiler JR. 2003. Impact of a Tethyan circumglobal passage on ocean heat transport and 'equable' climates. Paleoceanography 18(1).

Huber M, Sloan LC. 1999. Warm climate transitions: A general circulation modeling study of the late Paleocene thermal maximum ( $56 \mathrm{Ma})$. J. Geophys. Res. 104: 16633-16655.

Huber M, Sloan LC. 2001. Heat transport, deep waters, and thermal gradients: Coupled simulation of an Eocene greenhouse climate. Geophys. Res. Lett. 28(18): 3481-3484.
Kirk-Davidoff DB, Schrag DP, Anderson JG. 2002. On the feedback of stratospheric clouds on polar climate. Geophys. Res. Lett. 29: DOI 10.1029/2002GL014659.

Klein SA, Hartmann DL. 1993. The seasonal cycle of low stratiform clouds. J. Climate 6(8): 1587-1606.

Korty RL, Emanuel KA. 2007. The dynamic response of the winter stratosphere to an equable climate surface temperature gradient. $J$. Climate 20: 5213-5228.

Korty RL, Schneider T. 2007. A climatology of the tropospheric thermal stratification using saturation potential vorticity. J. Climate 20: $5977-5991$.

Korty RL, Emanuel KA, Scott JR. 2008. Tropical cyclone-induced upper-ocean mixing and climate: Application to equable climates. $J$. Climate in press.

Kyle HL, Hucek RH, Vallette BJ. 1991. Atlas of Earth's radiation budget as measured by Nimbus-7: May 1979-May 1980. http://ntrs.nasa.gov/archive/nasa/casi.ntrs.nasa.gov/ 19910015406_1991015406.pdf

Lian MS, Cess RD. 1977. Energy-balance climate models: Reappraisal of ice-albedo feedback. J. Atmos. Sci. 34(7): 1058-1062.

Lindzen RS, Farrell B. 1980. The role of polar regions in global climate, and a new parameterization of global heat transport. Mon Weather Rev. 108: 2064-2079.

Lunkeit F, Böttinger M, Fraedrich K, Jansen H, Kirk E, Kleidon A, Luksch U. 2005. Planet Simulator Reference Manual. http://www.mi.uni-hamburg.de/fileadmin/files/forschung/theomet/ planet_simulator/downloads/PS_ReferenceGuide.pdf

Markwick PJ. 1998. Fossil crocodilians as indicators of late Cretaceous and Cenozoic climates: Implications for using palaeontological data in reconstructing palaeoclimate. Palaeogeogr. Palaeoclimatol. Palaeoecol. 137(3-4): 205-271.

Moran K, Backman J, Brinkhuis H, Clemens SC, Cronin T, Dickens GR, Eynaud F, Gattacceca J, Jakobsson M, Jordan RW, Kaminski M, King J, Koc N, Krylov A, Martinez N, Matthiessen J, McInroy D, Moore TC, Onodera J, O'Regan M, Pälike H, Rea B, Rio D, Sakamoto T, Smith DC, Stein R, St John K, Suto I, Suzuki N, Takahashi K, Watanabe M, Yamamoto M, Farrell M, Frank M, Kubik P, Jokat W, Kristoffersen Y. 2006. The Cenozoic palaeoenvironment of the Arctic Ocean. Nature 441: 601-605.

Nakamura M, Stone PH, Marotzke J. 1994. Destabilization of the thermohaline circulation by atmospheric eddy transport. J. Climate 7: $1870-1882$.

Norris RD, Bice KL, Magno EA, Wilson PA. 2002. Jiggling the tropical thermostat in the Cretaceous hothouse. Geology 30(4): 299-302.

North GR. 1975. Theory of energy-balance climate models. J. Atmos. Sci. 32(11): 2033-2043.

North GR, Cahalan RF, Coakley JA Jr. 1981. Energy balance climate models. Rev. Geophys. Space. Phys. 19: 91-121.

Ohring G, Adler S. 1978. Some experiments with a zonally averaged climate model. J. Atmos. Sci. 35(2): 186-205.

Otto-Bliesner BL, Upchurch GR. 1997. Vegetation-induced warming of high-latitude regions during the late Cretaceous period. Nature 387: 804-807.

Pagani M, Zachos JC, Freeman KH, Tipple B, Bohaty S. 2005. Marked decline in atmospheric carbon dioxide concentrations during the Paleogene. Science 309: 600-603.

Pearson PN, Palmer MR. 2000. Atmospheric carbon dioxide concentrations over the past 60 million years. Nature 406: 695-699.

Pearson PN, Ditchfield PW, Singano J, Harcourt-Brown KG, Nicholas CJ, Olsson RK, Shackleton NJ, Hall MA. 2001. Warm tropical sea surface temperatures in the Late Cretaceous and Eocene epochs. Nature 413(6855): 481-487.

Peixoto JP, Oort AH. 1992. Physics of Climate. American Institute of Physics: Melville, NY.

Peters RB, Sloan LC. 2000. High concentrations of greenhouse gases and polar stratospheric clouds: A possible solution to high-latitude faunal migration at the latest Paleocene thermal maximum. Geology 28(11): 979-982.

Phillips NA. 1956. The general circulation of the atmosphere: A numerical experiment. O. J. R. Meteorol. Soc. 82: 123-164.

Pierrehumbert RT. 2002. The hydrologic cycle in deep-time climate problems. Nature 419(6903): 191-198.

Ramanathan V, Cess RD, Harrison EF, Minnis P, Barkstrom BR Ahmad E, Hartmann D. 1989. Cloud-radiative forcing and climate: results from the earth radiation budget experiment. Science 243(4887): 57-63.

Raymond DJ. 1995. Regulation of moist convection over the west Pacific warm pool. J. Atmos. Sci. 52(22): 3945-3959. 
Roche DM, Donnadieu Y, Puceat E, Paillard D. 2006. Effect of changes in delta $0-18$ content of the surface ocean on estimated sea surface temperatures in past warm climate. Paleoceanography 21(2):

Sasamori T. 1968. The radiative cooling calculation for application to general circulation experiments. J. Appl. Meteorol. 7: 721-729.

Schneider T, Walker CC. 2006. Self-organization of atmospheric macroturbulence into critical states of weak nonlinear eddy-eddy interactions. J. Atmos. Sci. 63: 1569-1586.

Schouten S, Hopmans EC, Schefub E, Damste JSS. 2002. Distributional variations in marine crenarchaeotal membrane lipids: A new tool for reconstructing ancient sea water temperatures? Earth and Planetary Science Letters 204: 265-274.

Sellers WD. 1969. A global climate model based on the energy balance of the earth-atmosphere system. J. Appl. Meteorol. 8: 392-400.

Shell KM, Somerville RCJ. 2005. A generalized energy balance climate model with parameterized dynamics and diabatic heating. J. Climate 18(11): 1753-1772.

Shellito CJ, Sloan LC, Huber M. 2003. Climate model sensitivity to atmospheric $\mathrm{CO}_{2}$ levels in the early-middle Paleogene. Palaeogeogr. Palaeoclimatol. Palaeoecol. 193(1): 113-123.

Slingo A, Slingo J. 1991. Response of the National Center for Atmospheric Research Community Climate Model to improvements in the representation of clouds. J. Geophys. Res. 96: 15 341-15357.

Sloan LC, Pollard D. 1998. Polar stratospheric clouds: A high latitude warming mechanism in an ancient greenhouse world. Geophys. Res. Lett. 25(18): 3517-3520.

Sloan LC, Rea DK. 1995. Atmospheric carbon dioxide and early eocene climate: A general circulation modeling sensitivity study. Palaeogeogr. Paleaoclimatol. Paleaoecol. 119: 275-292.

Sloan LC, Walker JCG, Moore TC, Rea DK, Zachos JC. 1992. Possible methane-induced polar warming in the early Eocene. Nature 357(6376): 320-322.

Sluijs A, Schouten S, Pagani M, Woltering M, Brinkhuis H, Sinninghe Damsté JS, Dickens GR, Huber M, Reichart G-J, Stein R, Matthiessen J, Lourens LJ, Pedentchouk N, Backman J, Moran K. 2006. Subtropical Arctic ocean temperatures and Palaeocene/Eocene thermal maximum. Nature 441: 610-613.

Soden BJ, Held IM. 2006. An assessment of climate feedbacks in coupled ocean-atmosphere models. J. Climate 19(14): 3354-3360.

Sokolov AP, Stone PH. 1998. A flexible climate model for use in integrated assessments. Clim. Dyn. 14(4): 291-303.
Stone PH. 1972. A simplified radiative-dynamical model for the static stability of rotating atmosphere. J. Atmos. Sci. 29: 405-418.

Stone PH, Yao MS. 1987. Development of a two-dimensional zonally averaged statistical-dynamical model. 2: The role of eddy momentum fluxes in the general-circulation and their parameterization. J. Atmos. Sci. 44(24): 3769-3786.

Stone PH, Yao M-S. 1990. Development of a two-dimensional zonally averaged statistical-dynamical model. 3: The parameterization of the eddy fluxes of heat and moisture. J. Climate 3: 726-740.

Tiedtke M. 1993. Representation of clouds in large-scale models. Mon. Weather Rev. 121(11): 3040-3061.

Trenberth KE, Caron JM. 2001. Estimates of meridional atmosphere and ocean heat transports. J. Climate 14: 3433-3443.

Trenberth KE, Stepaniak DP. 2003. Covariability of components of poleward atmospheric energy transports on seasonal and interannual timescales. J. Climate 16: 3691-3705.

Tripati AK, Delaney ML, Zachos JC, Anderson LD, Kelly DC, Elderfield H. 2003. Tropical sea-surface temperature reconstruction for the early Paleogene using $\mathrm{Mg} / \mathrm{Ca}$ ratios of planktonic foraminifera. Paleoceanography 18(4): 1-13.

Upchurch GR, Otto-Bliesner BL, Scotese C. 1998. Vegetation-atmosphere interactions and their role in global warming during the latest cretaceous. Phil. Trans. R. Soc. London Series B-Biological sciences 353(1365): 97-111.

Weaver C, Ramanathan V. 1995. Deductions from a simple climate model: Factors governing surface temperature and atmospheric thermal structure. J. Geophys. Res. 100: 11 585-11 591.

Wing SL, Greenwood DR. 1993. Fossils and fossil climate: The case for equable continental interiors in the Eocene. Phil. Trans. R. Soc. London Series B-Biological sciences 341(1297): 243-252.

Xu KM, Krueger SK. 1991. Evaluation of cloudiness parameterizations using a cumulus ensemble model. Mon. Weather Rev. 119(2): 342-367.

Yao MS, Stone PH. 1987. Development of a two-dimensional zonally averaged statistical dynamic model. 1: The parameterization of moist convection and its role in the general circulation. J. Atmos. Sci. 44(1): 65-82.

Zachos JC, Stott LD, Lohmann KC. 1994. Evolution of early Cenozoic marine temperatures. Paleoceanography 9(2): 353-387.

Zachos J, Pagani M, Sloan L, Thomas E, Billups K. 2001. Trends, rhythms, and aberrations in global climate 65 Ma to present. Science 292(5517): 686-693. 